\title{
- La concepción de sacramento en San Agustín
}

Recogidas las conclusiones de los estudios sobre los autores precedentes a San Agustín y también las conclusiones del estudio filológico del "sacramentum" en la obra agustiniana ${ }^{1}$, tenemos la pista libre para caminar expeditos por ella. En nuestro estudio trataremos de seguir a Agustín a través de isus textos, para comprender el sentido general de su temática. Y ante todo será necesario buscar la idea de fondo, la línea directiva de las diferentes significaciones de las palabras y de su contenido. Porque hemos convenido en que es necesario que en la compleja trama de las significaciones exista una verdad latente que dé unidad al edificio agustiniano. Sería ridículo que se pensase en desligar la sacramentaria agustiniana de las demás partes del espíritu de Agustín. Aunque aparentemente carezca de unidad ese espíritu, sin embargo no podemos creer que en su pensamiento esa unidad no subsista, a pesar de lo circunstancial de la mayor parte de su obra.

Se han estudiado, por separado, los signos ${ }^{2}$ tanto en lo filosófico como en lo filológico y en lo teológico, y se ha llegado a los sacramentos, calmándose los estudiosos con una definición tan imprecisa, como declaratoria, cual es sacramentum, id est signum sacrum ${ }^{3}$, que luego analizaremos. Couturier nos ha abiento un camino que necesita una profundización y una situación en el cuadro de lo agustiniano: es Cristo, como

1 Cfr. J. MoRÁN, "Mysterium y "sacramentum" hasta San Agustín": Estudio Agustiniano 4 (1969) 79-107.

2 Cfr. K. KUYPERs, Der Zeichen-und Wortbegriff im Denken Augustirs, Amsterdam 1934; R. A. Markus, "Sit. Augustine on Signs": Ohronesis 2 (1957) 60-83; A. BoRsT, Der Turmbau von Babel: Geschichte der Meinungen über Ursprung und Vielfalt der Sprachen und Völker. Band II/1, Stuttgart 1958 (dedica a San Agustín, 391-404); A. HoLl, Die Welt der Zeichen bei Augustin: Religionsphänomenologische Analyse des 13. Buches des Confessiones, Wien 1963; F. Soria, "La teoría del signo en san Agustín": La Ciencia I'omista 92 (1965) 357-396, etc.

3 De civ, Dei X, 5, PL, 41, 282. 
centro de este edificio de símbolos, de signos, de sacramento ${ }^{4}$. Diríamos, Cristo como sacramento primordial, dado que es de El de donde brotan los sacramentos y me atrevería a decir, con Agustín, que la misma Iglesia nace a través de los sacramentos ${ }^{5}$.

Siendo esto así, podríamos preguntarnos: ¿Por qué Cristo se constituye en centro y más todavía por qué todo se convierte en signo; en sacramento de Cristo? ¿Por qué le ha dado a Agustín por hacer girar todo en torno a Cristo y construye toda una simbólica cristocéntrica? En otros términos, ¿es ésta una teoría especial, inventada o redescubierta para explicar los sacramentos, o más bien es aplicación de una teoría más amplia de Agustín? Sabemos del mismo Agustín que "las cosas sorprendentes y maravillosas que hizo nuestro Señor Jesucristo son obras y palabras (opera et verba); obras porque son hechos (facta), y palabras porque son signos (signa')" 6 . Y los milagros que hizo Cristo son obras divinas "quae ad intelligendum Deum de visibilibus admonent humanam mentem" ". A este respecto los textos agustinianos hablan muy claro y nos están insinuando que se trata de una teoría que ya desde el principio está presente en el pensamiento de Agustín. Tras mucho laboreo intelectual ha llegado sin duda, por una reflexión personal, a su aplicación cristiana.

TEORÍA DE LA “ADMONICIÓN".

Como presupuesto al estudio del sacramento, tenemos que exponer brevemente el sentido de la teoría de la "admonición". Desde las primeras obras de Agustín topamos con una serie de términos que nos indican algo, aunque nos resistamos a creer que tenía perfectamente lograda ya su teoría, que con los años fue madurando y aplicando progresivamente ${ }^{8}$. Esos términos muy significativos son los siguientes: admonere,

4 C. Couturier, "Sacramentum et mysiterium dans l'oeuvre de saint Augustin": Etudes Augustiniennes, Paris 1953, 266; P. Th. CAMELot, "Sacramentum". Notes de théologie sacramentaire augustinienne": Revue Thomiste 57 (1957) 429-449.

5 Aunque ordinariamente parezca lo contrario, sin embargo algunos textos nos invitan a esta meditación que espera ahondamiento, cfr. In Jo. Evang. tr. 9, 10, PL. 35, 1463; De symb. ad catech. 6, 15, PL. 40, 645.

6 In Jo. Evang. tr. 44, 1, PL. 35, 1713.

7 Id. tr. 24, 1, PL. 35, 1502-1503.

8 Cfr. J. Morấn, "La teoría de la admonición en los Diálogos de San Agustín": Augustinus (Homenaje al P. Victorino Capánaga, II), Madrid 1968, 257-271; "La teoría de la admonición en las Confesiones de San Agustín". Augustinianum 8 (1968) 147-154. 
commonere, commonefacere, commemonare, in cogitationem faciunt venire, exercitare mentem, etc. Por otra parte, notamos una marcada tendencia a hablar de signa, de verba, de visa. Y en una de sus obras, en diálogo con su hijo Adeodato, trata ya expresamente el problema de los signos, estribando sobre todo en las palabras ${ }^{\circ}$. Esta tendencia se continúa a lo largo de toda su vida, aunque quizá cambiando la terminología por vocablos más bíblicos.

Esto que en el fondo parece inocuo, comporta una teoría muy profunda que le capacita para hablar de ese modo. Es indudable que de principio más que de ninguna otra doctrina le nace del neoplatonismo o del platonismo con un colorido ambrosiano, que le ha conducido a ver el mismo punto en lo escriturístico ${ }^{10}$. Agustín, a mi juicio, ha meditado mucho en el mundo como sombra. Aquellas anotaciones imprecisas de la reminiscencia en los Soliloquios ${ }^{11}$ y en el De quantitate animae ${ }^{12}$, que en las Retractationes ${ }^{13}$, cuando su doctrina está ya elaborada, las interpreta en sentido de inconsciente que pasa a la consciencia, desempeñan en este ambiente un papel decisivo. Agustín ha insistido en su primera etapa sobre todo en el espiritualismo y en el idealismo, en la división platónica de los dos mundos, el inteligible y el sensible, de los que aquél es el esencial y éste se reduce a una sombra o imagen de aquél, llamada, por otro flanco, a esencializarse con el mundo superior ${ }^{14}$.

Desde que acepta el principio de creación, medita la necesidad de un rechace de la reminiscencia, pero también de una sustitución porque el problema subsiste, a pesar de la creación. Dios crea y crea las cosas por voluntad y las crea buenas. Y desde el instante en que Dios, por pura bondad, pone, por hablar de algún modo, los seres fuera de sí, éstos se convierten en signos de la bondad de Dios, en llamadas de su presencia, en voz muda de su actualidad y de su operación en el mundo, en "admo. ción" al agradecimiento, al reconocimiento y al desarrollo colaborando

9 Se trata como es sabido del libro De magistro, sobre el que abunda también la bibliografía, a la que remitimos.

10 Cfr. P. Courcelle, Recherches sur les Confessions de saint Augustin, Paris 1950. 130 ; también P. Rollero. La "expositio evangelii secundum Lucam" di Ambrogio come fonte della esegesi agostizilana, Torino 1958; G. FERRETr, L'influsso di S. Ambrogio in S. Agostino, Faenza 1951.

11 Solil. II, 20, 35, PL. 32, 902-903.

12 De quant. anim. 20, 34, PL. 32, 1055.

13 Retract. I, 4. 4, PI. 32, 590; 8, 2, PL. 32, 594.

14 En el De ordine I. 11. 31-32, PL. 32, 992-994 habla de ello, aunque luego on Retract. I. 3, 2, PL. 32, 588-589 tenga que hacer una reinterpretación sobse todo en relación con los textos bíbliços que había aducido antes. 
con $E l$. La realidad creada se torna en expresión de Dios, en sacramento de El.

Dios crea también al hombre a quien sirven las cosas, que puede entender el grito callado de la realidad y alzarse al conocimiento del Creador ${ }^{15}$. Pero, a su vez, en el hombre se presencializa El y el hombre vive conscientemente unido a Dios y palpa su presencia en cada uno de sus actos ${ }^{16}$. Sin embargo, esto que era la esencia, lo ontológico del hombre agustiniano, ahora, en el realismo de la historia humana, resulta una anormalidad. El hombre vive desheredado de su consciencia de Dios, vive y se mueve en Dios, porque Dios está en él, pero él no está con Dios ${ }^{17}$. La creación sigue siendo expresión de Dios, responde a quien $l_{d}$ interroga, pero solamente entiende su respuesta quien puede juzgar, y sólo está capacitado para juzgar quien en su intimidad vive con la Verdad', con Dios, sin apego a lo pasajero ${ }^{18}$.

Todo aquel mundo que el hombre portaba en la intimidad y se identificaba con Dios y del que antes era consciente, ahora es pura presencia en el hombre, es decir inconsciencia, ya que viene al tiempo mente sopita ${ }^{19}$. Para hacer tornar el hombre a la consciencia de Dios y de su mundo interior, imagen y expresión de Dios, la más auténtica, precisa de una llamada, de un aviso, de un golpe de atención, de una "admonición", o de una "conmonición". Todo lo creado se convierte de este modo también en signo de la realidad interior y como signo llama a lo significado. Las sombras proyectadas en el mundo son signos de la presencia de Dios en él y son llamadas para el hombre, para que él tome consciencia de su presencia en sí mismo y dé sentido de ese modo a las cosas. La realidad se convierte en símbolo, en figura, en sacramento, en signo, en misterio. Nos hallamos envueltos en misterio por todas partes.

El hombre, al nacer, trae consigo todo lo necesario para vivir racionalmente, pero necesita ser despertado a esa vida. Trae consigo los valores, que son expresión y presencia. de Dios en el interior, y como inicia su vida por los sentidos, la realidad' externa se le convierte en "admoni-

15 Las ascensiones del libro de las Confesiones, del De Trinitate y sobre todo de las Enarrationes in psalmos, pasando antes por el De libero arbitrio y el De vera religione son una prueba de este aserto.

16 La teoría de la imagen de Dios y de la memoria Dei adquiere en este sentido todo su valor, y nos vemos excusados de citar la bibliografía a este respecto, porque es ya conocida de nuestros lectores.

17 Cfr. nuestra obra El hombre frente a Dios. El proceso humano de la ascensión a Dios según san Agustín, Valladolid 1963.

18 Los textos a este respecto se multiplican y es inútil citarlos aquí.

19; En más de una ocasión Agustín usa esta expresión. 
ción" continuada, en signo de aquella presencia, que le obliga a tomar consciencia. El punto de referencia será ya claro. Todo quedará interpretado a esta luz con la doble vertiente. Se tratará de invención, de descubrimiento, no de creación, o si se prefiere, habría aquí una nueva creación, que sería iluminación, es decir, paso de la presencia a la consciencia. El hombre es radicalmente completo desde la creación, pero tiene que ir desarrollando su potencialidad a base de la consciencia y reflexión que usa de los signos para perfeccionarse y llegar a la madurez total. A este sentido reducirá la teoría del conocimiento, la ética, la cosmología en un mundo que es invitación y presencia de Dios, la matemática, etc. Por la unidad de valores en aspiración se forma la comunidad y la comunión de los hombres, cuyos lazos se aprietan más y se solidifican cuanto más consciencia adquieren de esa unidad y de la comunidad y comunión por la que tienen que sacrificarse y a la que se deben para estrechar la fraternidad universal. El logro de una cierta consciencia de la comunión humana es a su vez signo y llamada a la consumación total de la unidad, que se sentido escatológico final de la fraternidad entre los hombres.

Cristo en el CENTRo.

Y con esta teoría de orden filosófico que, una vez convertido, Agustín no puede considerar como algo aparte, se lanza a la reflexión en torno al cristianismo. La filosofía se convierte en pedagogía de la religión y concluye por identificarlas, reduciéndolo todo a un pensamiento incluyente, en el que existirá una interpretación racional del misterio y una inteligencia misteriosa de la razón. Agustín se ha debatido en la construcción de este espíritu y ha tardado en madurar plenamente en él. No entramos a dilucidar cuál ha sido el momento en que podemos asegurar que ha logrado ya la rienda teológica de su montaje espiritual. A grandes rasgos diríamos que es en torno al año 400 y que no es tanto el problema de la gracia y de la predestinación, cuanto el misterio de Cristo y de la Iglesia el que tiene planteado muy seriamente y resuelve hacia esa época. Cristo se constituye en ejemplo y modelo de gracia y de predestinación y lo que le preocupa a Agustín es la situación de Cristo, ese Cristo que ha de integrar por fuerza en la naturaleza humana y que le ayudará a la solución del gran misterio de las relaciones entre la libertad humana y la gracia. Donde hay que poner el acento es en el estudio de Cristo y de su significado extraordinario en el agustinismo. 
Para no alargarnos en este punto, que esperamos desarrollar en otro lugar, nos atendremos brevemente a las Confesiones, en las que Agustín proyecta su mundo, el mundo de sus convicciones de ahora a aquella convensión y a aquella primera duda sobre Cristo ${ }^{20}$. Agustín está empeñado en hacer brillar a Cristo y ya desde la lectura del Hortensio, que le disgusta por no hallar en él el nombre de Cristo ${ }^{21}$, pasando luego por el engaño maniqueo, donde se le hacía sonar continuamente el nombre de Cristo envuelto en misterio trinitario, pero que en realidad le ofrecía un Cristo filosófico ${ }^{22}$, hasta su encuentro con los neoplatónicos y con Ambrosio su problema es siempre el mismo. Había mamado el nombre de Cristo con la leche materna ${ }^{23}$ y no le abandonará en toda su vida ni en medio de sus errores ${ }^{24}$. Una búsqueda y una integración era su única posibilidad. Y esa será su tarea: la verdad, la sabiduría, el mal, el pecado, el orgullo, la soberbia.

Necesita un Cristo para la liberación del alma. Su crisis interior va en aumento. Ha visto en el neoplatonismo un Verbo, alejado del hombre, excesivamente divino, para que el hombre pueda ponerse en contacto con él ${ }^{25}$. Necesita un auténtico mediador. Los filósofos se divirtieron con el señuelo de la patria, pero les faltaba el camino ${ }^{26}$. No podían allanarse a la humillación. Agustín necesita de liberación y de purificación y ve fracasar ante sí todas las filosofías. Descubre el secreto en Ambrosio que ha llegado a una cierta integración ${ }^{27}$. Y comienza a leer a San Pablo. Había perdido ya la confianza en lo humano, pues sus éxtasis frustrados le han conducido al borde de la desesperación ${ }^{28}$. Y leyendo a San Pablo, éste le descubre el misterio, el secreto, el sacramento que es Cristo, "sanans tumorem et nutriens amorem" 29. San Pablo le enseña, piensa él, cuanto le enseñaban los filósofos, pero aquí cum commendadatione gratiae ${ }^{30}$. Nota la diferencia, y hacía antes un parangón con

20 Cfr. C. VACA, "Cristo en la vida de san Agustín": Augustinus (= Homenaje al P. Victorino Capánaga, I). Madrid 1967, 423-432.

21 Confess. III, 4, 8, PL. 32, 686.

22 Id. III, 6, 10, PL. 32, 686-687.

23 Vid. n. 21

24 Id. V. 9, 16, PL. 32, 713: 10, 20, col. 715-716; VII, 19, 25, col. 746.

25 Id. VII, 20, 26, PL. 32,$747 ; 18,24$, col. $745 ; 19,25$, col. $746 ; 9$, 13-14, sol. $740-742$.

26 Id. VII, 21, 27, PL. 32, 748.

27 Id. VI. 4, 5-6, PL. 32, 721-722.

28 Cfr. P. Courcense, Recherches sur les Confessions de saint Augustin, Paris 1950, 157-167.

29 Confess. VII, 18, 24, PL. 32, 745 ,

30 Id. VII, 21, 27, col. 747 . 
San Juan: ibi legi... ibi non legi... ${ }^{31}$. En los filósofos le había faltado la encarnación, el Cristo que se anbonada y baja a la humanidad y la toma haciéndose hombre y elevando a éste ${ }^{32}$. San! Pablo le ha revelado el misterio y Agustín queda sorprendido. Trata de integrar. No quiere desprenderse de su filosofía, pero la ve ya incompleta y desde entonces la única verdadera filosofía es la religión, que le exige humildad, sometimiento a la encarnación de Cristo, sin que el hombre le mancille. Y su pecado como el de todos los filósofos consistía en el orgullo, en creer que podían ser redimidos, salvados, liberados y elevados por sí mismos.

Ya ante Cristo como única solución al viejo problema planteado por la filosofía y vivido en propia carne, colocará a Cristo en el centro y no se desprenderá más de El. Desde ese instante la filosofía queda trocada en religión y no se separarán ya más esos dos elementos, concretándose su vida en una tarea de integración y búsqueda de salida hónrosa a los múltiplies problemas planteados. A esto mismo se reducirá su pensamiento ya maduro en La Ciudad de Dios. En sus diez primeros libros seguirá en lo social el mismo proceso que ha seguido en las Confesiones en lo personal. Y si en sul autobiografía Cristo se manifestó como el único capaz de superar las filosofías y de dar satisfacción y cumplido a los deseos de verdad y de elevación que abriga el corazón del hombre, aquí Cristo culminará en el centro de la historia. Caídos a sus pies los ídolos de todas las filosofías, incluso del platonismo ${ }^{33}$, y en precedencia del materialismo ${ }^{34}$, edifica un espíritu, situando en su verdadero puesto a Cristo y su religión, como purificación del alma, para la que resultaban impotentes también a un examen crítico las teurgias y las artes a que apelaban Apuleyo y Porfirio ${ }^{35}$. Y después de refutar a Porfirio y de ver las inconsecuencias de los plattónicos, concluye con esa vía real para la liberación del alma que es la religión cristiana ${ }^{\mathbf{3 6}}$.

A partir de esta demostración que concluye los $\mathrm{X}$ primeros libros de La Ciudad de Dios se hace comprensible todo. Los libros siguientes

31 Id. VII, 9, 13-14, col. 740-741.

Así aparece en los textos citados en las notas precedentes.

33 A partir del libro VIII de La Ciudad de Dios en el que se hace un recorrido de la historia de la filosofía, quedan en juego los platónicos y a ellos irá dirigida luego la discusión.

34 Los V primeros libros del De civitate Dei y todavía se prosigue el argumento en el VI y VII desbaratan el materialismo en sus ramificaciones de culto a los dioses.

35 De civ. Dei X, 9, 1-2, PL. 41, 286-287; caps. 10-11 y luego continuará el tema a partir del cap. 23 hasta el final del libro.

36 Id. X, 32, 2, PL. 41, 313-315. 
se limitan a la historia del sacramento que es Cristo, de ese misterio, preanunciado como por venir, y anunciado ya cumplido. Existirán, pues, signos en una y otra época, de una única realidad, Cristo y su religión, "fuera de la cual nadie se ha liberado, nadie se libera y nadie se liberará". Cristo quedaba constituído en centro de la historia personal y de la historia social. Y todo se convertía en signo de El.

Agustín nos habla con verdadero realismo de ese Cristo que se hace hombre, siendo Dios, para elevar al hombre de la temporalidad a la eternidad. $Y$ es ése un pensamiento fundamental en el Santo, que repite en todos los tonos, profundizando en torno a él en la justificación por la encarnación y en la deificación del hombre, en su redención por la sangre y en la colaboración humana a la misma. En todo caso, Cristo debía ser hombre y Dios, "porque si no fuera hombre, no podría ser crucificado; si no fuera Dios, no se creería que no quiso lo que pudo, sino que no pudo lo que quiso; ni creeríamos que prefirió la justicia al poder, sino que le faltó poder" ${ }^{37}$. A Agustín le agrada considerar este misterio hondo y esta voluntad de Dios, porque así, al encarnarse, vence por medio del hombre al diablo, para que éste deje libre al hombre, a quien había subyugado ${ }^{38}$. Y así la sangre de Cristo es derramada como precio de esta redención, librando al hombre por ese precio de la prisión del diablo, "muriendo ahora los hombres como herederos de la gracia de Cristo, conocidos, predestinados y elegidos antes de la constitución del mundo, pues Cristo murió por ellos muerte de carne, no de espíritu" ${ }^{39}$. En el misterio de la encarnación y de la redención del hombre, el Santo ve otros frutos: la conciencia que el hombre ha de tomar por ese medio de su grandeza en el plano de Dios, la gracia que aparece en el hombre-Cristo sin mérito alguno precedente, el sometimiento de la soberbia y del orgullo humano, el ejemplo de obediencia que brinda Cristo de este modo ${ }^{40}$.

Tras un análisis de la encarnación, en busca de la felicidad y de la inmortalidad, en las que es imprescindible la fe, resume el pensamiento en la integración con la filosofía y termina como ha hecho antes en el De civitate Dei y en las Confesiones ${ }^{41}$. Este empeño por completar la

\footnotetext{
37 De Trin. XIII, 14, 18, PL. 42, 1028.

Id. XIII, 15, 19, PL. $42,1028-1029$.

$I b$.

Id. XIII, 17, 22, PL. 42, 1031-1032.

Id. XIII, 19, 24, PL. 42, 1033-1034.
} 
filosofía con Cristo es muy significativo. De ese modo la filosotia se convierte en religión y Cristo entra a formar pante, diría, de modo ontológico en la humanidad, pudiendo hablarse de una cristo-ontologia. $\mathrm{La}$ fe aparece como el primer requisito y su teoría general no es concebible ya sin Cristo.

Ahora bien, dadas estas premisas, la conclusión es ya evidente. Cristo se une a la naturaleza humana, la asume y la diviniza en cierta medida, se torna en elemento imprescindible de las relaciones del hombre con los valores. Y allí donde el hombre amaba la verdad y nada tan ardientemente amaba como la verdad, ahora ama a Cristo, aunque sea inconscientemente, porque Cristo es la verdad, y si la verdad ilumina en el interior, quien ilumina es Cristo, maestro interior. Siendo la gracia suprema la unión del Verbo con la naturaleza humana, toda otra gracia será participación de ésa, y se manifiesta como cristológica. Como esa gracia se revela a los hombres y los integra desde la encarnación al ser elevados por $\mathrm{El}$ y en $\mathrm{El}$, resulta que a partir de Cristo hay que entenderlo todo.

Las cosas nos hablaban de Dios, eran signos de su presencia y reclamaban al hombre a escuchar la voz de la verdad en la intimidad. Y ahora son signos de Cristo que es el Valor máximo e invitan al hombre a descubrir en sí mismos la iluminación del Verbo que es Cristo. Y Este se ha hecho imprescindible. En el plano providencial de Dios, el Antiguo Testamento aparece como símbolo, imagen y figura de Cristo, y los sacramentos de la Nueva Ley son signos de Cristo. En el realismo con que Agustín ha presentado toda la cristología, en esa divinización del hombre, en ese tender el hombre por el hombre-Cristo al Cristo-Dios, radica el pensamiento agustiniano. Cristo ha muerto por todos y ha justificado en su sangre al hombre, envolviéndose éste en su gracia desde el principio. Si Cristo es el ejemplo perfecto de la gracia, si es el modelo pleno de la predestinación, si es el maestro que enseña en la intimidad y hace despertar a la verdad, si desde el principio el hombre está injertado en Cristo, el "initium fidei" se comprende también como una gracia y pende de El. Todo hará referencia a Cristo, que se ha identificado con los valores que el hombre portaba en su interior, a cuya consistencia y realización era llamado. Diríamos que el hombre trae consigo una gracia, a partir de la encarnación de Cristo, y en previsión de El la traían quienes eseperaban en Cristo, en la Vieja Ley. En uno y otro caso se necesitaba algo que la hiciese surgir, la despertase y eso 
sería producir la gracia, es decir, hacer tomar consciencia y realización de una relación existente en la inconsciencia ${ }^{42}$.

Siendo Cristo centro de toda la vida humana y cristiana, aquello que antes fue una teoría filosófica, ahora, al trocarse en religión la filosofía, se convierte en teoría religiosa. $Y$ aquello que fue signo y admonición de un valor, se torna ahora en signo sagrado de alguien que ha ocupado el puesto de los valores en la persona humana. Agustín había echado en cara a los filósofos que su pecado había consistido en filosofar sin Cristo y en esperar la purificación y liberación del alma sin Mediador. Ahora su filosofar se concreta en filosofar con Cristo. Haciendo pie en este hecho, de Cristo imprescindible y Cristo centro, construye toda su teología. Su sacramentaria será una aplicación de su teoría más general.

Cristo ha divinizado a los hombres con su encarnación, ha conquistado la gracia para los mismos, y toda gracia, desde su encarnación, se revela como cristológica. La producción de la gracia se realizó una vez por todas y desde entonces no existe más que un despertar de esa gracia, con la necesidad de unos signos sensibles capaces de traerla a la mente y de hacer obrar en consecuencia. Así se comprenderá inmediatamente que sea Cristo quien bautiza, Cristo quien santifica o su Espíritu y que el sacramento sea una santificación visible.

\section{HACIA UNA COMPRENSIÓN DEL SACRAMENTO.}

Con estos precedentes quizá se nos haga más comprensible la concepción agustiniana de sacramento. Hemos apuntado en lo filológico los diversos sentidos y lo vamos a ver prácticamente en este texto:

"Sermonem ad altare Dei debemus hodie infantibus de Sacramento altaris. Tractavimus ad eos de sacramento Symboli, quod credere debeant: tractavimus de sacramento orationis Dominicae, quomodo petant; et de sacramento fontis et baptismi. Omnia haec et disputata audierunt, et tradita perceperunt: de Sacramento autem altaris sacri, quod hodie viderunt, nihil adhuc audierunt; hodie illis de hac re sermo debetur" 43.

Esta diversidad de empleos era reconocida también en la discusión

42 Las relaciones de esta gracia que es inconsciente con lo que se dio $\epsilon$ n llamar pecado original, que es también inconsciencia, aparecerían de este modo. Este quedaría radicalmente quitado por Cristo y el bautismo nos manifestaría que existe, pero que dejó de existir con Cristo y deja de existir visiblemente por ese signo sensible que manifiesta aquello.

43 Serm. 228, 3, PL. 38, 1102. 
del Concilio de Trento, por el Cardenal Seripando ${ }^{44}$. Y se atuvieron a una definición para poder condenar a los herejes que no comulgaran con ella, aunque expresamente no la dieron. Se pedía de hecho también la condenación de quien dijera que "todos los signos que en las Escrituras contienen una promesa, son sacramentos, como estos siete, por ejemplo, la oración, la limosna, la remisión de los pecados, etc." ${ }^{45}$. Agustín, mirado bajo este prisma, caminaría entre dos fuegos. Los católicos lo salvarían con una distinción entre sacramento en sentido propio y en sentido impropio. Pero tendríamos que decir, como hemos señalado, con algún, autor, que su doctrina sacramentaria general no es clara ni está evolucionada, si bien contiene muchos elementos dignos de consideración. San Agustín distingue en el sacramento dos cosas: lo visible y lo invisible, aunque haremos algún reparo a ese segundo aspecto. Aquello es pasajero y esto sería permanente: el signo pasa, lo significado permanece:

"De sacramento sane quod accipit, cum ei bene commendatum fuerit, signacula quidem rerum divinarum esse visibilia, sed res ipsas invisibiles in eis honorari..." 46.

Esto nos lleva de la mano al examen de toda la temática sacramentaria agustiniana. Porque está aplicando su teoría general a la teología, con un doble de visible e invisible, siendo lo visible los signos, y lo invisible las cosas divinas (res divinae).

Insistiendo en ese doble, llega a lo carnal y a lo espiritual, de tal suerte que entonces lo esencial en el sacramento radica en comprenderlo spiritualiter y no carnaliter, pues aquel que entiende el signo sacramental carnalmente queda sometido y esclavizado por él, mientras que quien lo entiende espiritualmente se ve abierto a la libertad de lo significado y a la plena comprensión. Desde esta perspectiva comprende los sacramentos del Viejo y del Nuevo Testamento y da solución a sus relaciones mutuas. ¿Por qué no murieron muchos judíos, comiendo aquel maná?, se pregunida Agustín. Y contesta:

44 Concilii Tridentini Actorum. Pars altera. Acta post Sessionem Tertiam usque ad Concilium Bononiam translatum. Collegit edidit illustravit Stephanus EHses. Editio secunda stereotypa, Friburgi Brisgoviae 1964, V, 962.

$45 \quad I b . \mathrm{V}, 963$.

46 De catech. rud. 26, 50, PL. 40, 344; cfr. también De civ. Dei X, 5, PL. 41, 282; C. Faustum manich. XIX, 11-12, PL. 42, 355; In Jo. Evang. tr. 26, 11, PL. 35, 1611; En. in ps. 77, 2, PL. 36, 983-984, etc. 
"Quia visibilem cibum spiritualiter intellexerunt, spiritualiter esurierunt, spiritualiter gustaverunt, ut spiritualiter satiarentur. Nam et nos hodie accipimus visibilem cibum; sed aliud est sacramentum, aliud virtus sacramenti 47.

Ha aparecido en el texto un nuevo concepto que será necesario considerar con detención. Se nos dice que aliud est sacramentum, aliud virtus sacramenti, y esta misma distinción es posible que entre en el conjunto de dobles que estamos descubriendo en la doctrina. Quizá al final comprendamos mejor su significado.

Subrayando otro hecho que nos conduce a la misma conclusión, Agustín compara los sacramentos a quaedam quasi verba visibilia. El verbum visibile tiene una grandísima importancia en él para los signos. Basta profundizar un poco en su significado para darnos cuenta de cuanto Agustín trata de insinuarnos. Toda palabra comporta dos cosas: el sonus transiens y la virtus maniens, aquél desaparece, pero permanece esa virtud que es lo transmitido por la palabra. Y esto mismo pasa en los sacramentos. A través de la palabra pasajera se nos hace tomar consciencia del valor ya existente en la intimidad, y a través del sacramento de la gracia invisible. Antes se llegaba al signum sacrum, y ahora se llega a verba sacrosancta:

"Quid enim sunt aliud quaeque conporalia sacramenta, nisi quaedam quasi verba visibilia, sacrosancta quidem, verumtamen mutabilia et temporalia? Deus enim aeternus est, nec tamen aqua et omnis illa actio corporalis, quae agitur cum baptizamus, et fit, et transit, aeterna est: ubi rursus etiam illae syllabae celeriter sonantes et transeuntes, cum dicitur, Deus, nisi dicantur, non consecrantur" 48.

$\mathrm{Y}$ es que todos los signos son eso, como palabras visibles (quasi quaedam verba visibilia) ${ }^{49}$. Y a ello aplicará toda su teoría del lenguaje expresada ya en el De magistro y ampliada en otras ocasiones ${ }^{50}$.

Hay todavía otra constatación que hacer en este doble de que tan abundantemente nos habla el Santo. En alguna ocasión leemos en él una distinción que quizá pueda comprenderse también en esta dirección.

47 In Jo. Evang. tr. 26, 11, PL. 35, 1611.

48 C. Faustum manish. XIX, 16, PL. 42, 356-357; cfr. también In Jo. Evang. tr. 80, 2-3, PL. 35, 1839-1840.

49 De doctr. christ. II, 3, 4, PL. 34, 37.

50 La bibliografía sobre el De magistre es ampliamente conocida y su tema principal, ya estudiado también por nosotros en atra parte. 
Se trata de una santificación visible y de una santificación invisible. Tras hablar de una diferencia práctica, he aquí los términos con que se expresa:

\footnotetext{
"Prainde colligitur invisibilem sanctificationem quibusdam affuisse atque profuisse sine visibilibus Sacramentis, quae pro temporum diversitate mutata sunt, ut alia tunc fuerint, et alia modo sint: visibilem vero sanctificationem, quae fieret per visibilia sacramenta, sine ista invisibili posse adesse, non posse prodesse. Nec tamen ideo sacramentum visibile contemnendum est: nam contemptor ejus invisibiliter sanctificari nullo modo potest. Hinc est quod Cornelius et qui cum eo erant, cum iam invisibiliter infuso sancto Spiritu sanctificati apparerent, baptizati sunt tamen (Act. 8, 44-48) nec superflua judicata est visibilis sanctificatio, quam invisibilis jam praecesserat" 51 .
}

Quizá en este texto hallemos toda la doctrina del Santo sobre el sacramento y la interpretación de esa santificación visible, a la que precede la santificación invisible. Aparece también aquí esa famosa distinción, sobre todo en la controversia donatista, entre el adesse y el prodesse. Y hay otro hecho que más tarde analizaremos también: el desprecio de la santificación visible, es decir, del sacramento visible, incapacita para ser santificado invisiblemente.

Destilemos unos primeros hechos fundamentales, que nos conducirán como de la mano a una inteligencia del sacramento:

a) En el sacramento, hallamos un doble, como una prolongación de la encarnación de Cristo: lo visible y lo invisible.

b) Aparecería en términos propios como signo visible de algo invisible, con las connotaciones que luego veremos.

c) En los textos hay otra distinción que es lo carnal y lo espiritual, que en principio se aplicaba a lo escriturístico, y que pasa a la interpretación de los signos y símbolos de la Escritura en referencia a los sacramentos. Jugará un papel primordial, con el fin de no entender carnalmente los signos ni materializarlos, quedando esclavizados por ellos.

d) Los signos vienen asimilados a la palabra visible, distinguiéndose en ella el sonus transiens y la virtus manens.

e) Siguiendo esta misma línea, se habla de una santificación visible debida a los sacnamientos visibles, y de una santificación invisible debida al Espíritu Santo y fruto del mismo. Agustín habla de los sacramentos de la Antigua Alianza, pero ya sabemos cuál es su pensamiento

51 Quaest. in Hept. III, 84, PL. 34, 713. 
a este respecto. El texto merece cita especial, aunque sea un poco largo, porque nos manifiesta un pensamiento y nos crea problemas, que esperan solución :

"Quomodo ergo et Moyses sanetificat et Dominus? Non enim Moyses pro Domino: sed Moyses visibilibus Sacramentis per ministerium suum; Dominus autem invisibili gratia per Spiritum sanetum, ubi est totus fructus etiam visibilium sacramentorum. Nam sine ista sanctificatione invisibilis gratiae, visibilia Sacramenta quid prosunt? Merito autem quaeritur utrum etiam ista invisibilis sanctificatio sine visibilibus sacramentis, quibus visibiliter homo sanctificatur, pariter nihil prosit: quod utique absurdum est. Tolerabilius enim quisque dixerit, sine illis istam non esse, quam si fuerit, non prodesse; cum in ista sit omnis utilitas illorum. Sed etiam hoc, quod sine illis ista esse non possit, quomodo recte dicatur, intuendum est. Nihil quippe profuit Simoni mago visibilis Baptismus, cui sanctificatio invisibilis defuit: sed quibus ista invisibilis, quoniam affuit, profuit, etiam visibilia Sacramenta perceperant similiter baptizati" 52.

La renovación interior por la gracia del Espíritu Santo será la santificación invisible, pero ¿qué es la santificación visible? Tal como se manifiesta en los textos sería la mera recepción del sacramento, pero el efecto de éste quedaría reducido a ser pura presencialidad y revelación.

\section{EN TORNO A UNA DEFINICIÓN.}

Con esto por delante, será necesario acercarse a una definición de sacramento en Agustín. Los sacramentos deben conservar alguna semejanza con la realidad de que son sacramkntos ${ }^{53}$. La semejanza les impone tomar el nombre de la cosa de que son semejanza. El famoso texto de Agustín, ya examinado en los diferentes tratadistas, nos obliga en el conjunto del tema a unas reflexiones. Dice así:

"Nonne semel inmolatus est Christus in seipso, et tamen in sacramento non solum per omnes Paschae sollemnitates, sed omni die populis immolatur, nec utique mentitur qui interrogatus eum responderit immolari? Si enim sacramenta quamdam similitudinem earum rerum quarum sacramenta sunt, non haberent, omnino sacramenta non essent. Ex hac

$52 \quad I b$. PL. 34, 712.

53 Cfr. M. F. BerRouARd, "Similitudo et la définition du réalisme sácramentel d'après l'Epître 98, 9-10 de saint Augustin": Studia Patristica VI/4 edited by F. L. Cross, Berlin 1962, 277-293. En otro sentido puede verse V. Grossi, "Il battesimo e la polemica pelagiana negli anni 411/413. (De peccatorum meritis et remissione- Epist. 98 ad Bonifacium)": Augustizianum 9 (1969) 30-61, para la Epist. 98, 54-61. 
autem similitudine plerumque etiam ipsarum rerum nomina accipiunt. Sicut ergo secundum quemdam sacramentum corporis Christi corpus Christi est, sacramentum sanguinis Christi sanguis Christi est, ita sacramentum fidei fides est. Nihil est autem credere, quam fidem habere. Ac per hoc cum respondetur parvulum credere, qui fidei nondum habet affectum, respondetur fidem habere propter fidei sacramentum, et convertere se ad Deum propter conversionis sacramentum, quia et ipsa responsio ad celebrationem pertinet sacramenti" 54 .

Se habla, pues, de una cierta semejanza (quadedam similitudo), pero no se nos expresa en qué consiste. A su vez se dice que secundum quemdam modum el sacramento del cuerpo de Cristo es el cuerpo de Cristo, y podríamos preguntar: ¿Cuál es ese quidam modus? ¿Es real, es místico, o es solamente inteligible a partir de esa semejanza que el sacramento mantiene de la realidad de que es sacramento? ¿Sería la aplicación de la teoría de la participación al sacramento o podría hablarse aquí de su realismo sacramental, al que han apelado otros? En el sacramento del bautismo del que se interroga Agustín más especialmente en esta Carta hay otra distinción. En el bautizado, cuando es infante, no existe la fe en la voluntad del cneyiente, pero se halla el sacramento de esa $f e . \mathrm{Y}$ distingue entonces entre mente annuene rem y plercipere ipsius rei sacramentum:

"Nam sicut credere respondetur, ita etiam fidelis vocatur, non rem ipsam mente annuendo, sed ipsius rei sacramentum percipiendo. Cum autem homo sapere coeperit, non illud sacramentum repetet, sed intelliget, ejusque veritati consona etiam voluntate coaptabitur. Hoc quamdiu non patest, valebit sacramentum ad eius tutelam adversus contrarias potestates; et tantum valebit ut si ante rationis usum ex hac vita emigraverit, per ipsum sacramentum commendante Ecclesiae charitate, ab illa condemnatione, quae per unum hominem intravit in mundum, christiano adiutorio liberetur. Hoc qui non credit et fieri non posse arbitratur, profecto infidelis est, etsi habeat fidei sacramentum; longeque melior est illo parvulus, qui etiamsi fidem nondum habeat in cogitatione, non ei tamen abicem contrariae cogitationis opponit, unde sacramentum salubriter percipit" 55.

Vamos señalando pistas solamente para extraer luego las conclusiones. Podríamos limitarnos al bautismo y al orden, como sacramentos plenarios, pues imprimen carácter; lo haremos en otra ocasión. Para una mejor inteligencia, recordemos todavía otro hecho: Agustín res-

54 Epist. 98, 9, PL. 33, 363-364.

55 Id. 9-10, PL. 33, 364. 
ponde a unas preguntas de Genaro, haciendo una nueva distinción que concurre a aclararnos los términos planteados: in memoriam e in sacramentum. Si alguien pudiera pensar que en el modo que escribía, se thataba de una mera recordación o de una reminiscencia o de una conmemoración, ahora declara:

"Hic primum oportet noveris diem Natalem Domini non in sacramentum celebrari, sed tantum in memoriam revocari quod natus sit, ac per hoc nihil opus erat, nisi revolutum anni diem, quo ipsa res acta est, festa devotione signari. Sacramentum est autem in aliqua celebratione, cum rei gestae commemoratio ita fit, ut aliquid etiam significari intelligatur, quod sancte accipiendum est. Eo itaque modo agimus Pascha, ut non solum in memoriam quod gestum est revocemus, sed etiam caetera quae circa ea attestantur, ad sacramenti significationem non omittamus... Transitus ergo de hac vita mortali in aliam vitam immortalem, hoc esit enim de morte ad vitam, in passione et resurrectione Domini commendatur" 56.

Los términos del problema están ya claros, aunque aparentemente sean oscuros para la interpretación desde nuestras concepciones. El sacramento, como todo signo, ha de tener una semejanza de la cosa significada y por esa semejanza a veces llamamos la realidad por ese nombre. Busquemos el ejemplo más claro para intentar una salida a los textos agustinianos, discordantes en apariencia. Tenemos el caso del bautismo. El bautizado decimos que tiene la fe propter fidei sacramentum, es decir, tiene la cosa significada - la fe- por el signo que la significa -el sacramento-, o sea en virtud de él, por la semejanza que el signo tiene de la cosa significada. Sin embargo la pregunta planteada es muy grave: ¿El sacramento da esa fe, la comunica, o es simplemente un signo manifestativo? Hablando de sacramento de algo, podemos interrogarnos: ¿De algo ya existente, o de algo que va a existir en virtud del mismo signo que lo significa? El bautismo es sacramento de la fe -sacramentum fidei-, ¿dde la fe ya existente, o que va a existir?

Hasta el presente, Agustín no nos ha presentado el tema de la causalidad sino sencillamente nos ha dicho que respondetur fidem habene propter fidei sacramentum y se dice además sacramento ut aliquid etiam significari intelligatur. Es, pues, sacramento de la fe y se dice sacramento porque significa la fe. $¿ L a$ causa el sacramento o simplemente la significa? 
Extrayendo las conclusiones de lo estudiado hasta ahora en San Agustín, tendríamos lo siguiente :

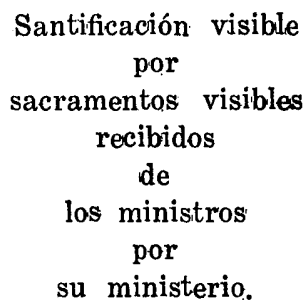

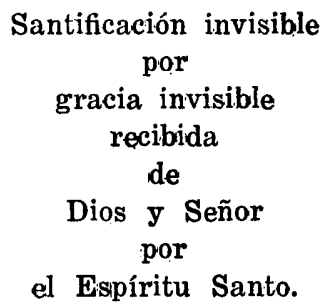

Todo el fruto y utilidad de los sacramentos visibles radica en la gracia y santificación invisible. Hablar de "fructus" y de "utilitas" o de "salubriter percipere es confesar el prodesse y no el adesse ${ }^{57}$. No obstante, podemos seguir preguntándonos todavía: ¿ ¿Será siempre necesaria la santificación invisible del Espíritu antes de la percepción del sacramento visible, que es santificación visible, de suerte que el sacramento sea signo de la santificación invisible operada ya por el Espíritu? Más aún: ¿Se da la santificación invisible antes de la perfección del sacramento, de tal suerte que no poner óbice consiste en tener esa santificación invisible, de la que va a ser signo el sacramento, y cuando se da óbice -falta la santificación invisible- existe el sacramento visible -adest-, pero no tiene su fruto y utilidad —non prodest-? Los textos que hemos analizado nos conducirían a esta conclusión.

Sin embargo, nos ha surgido un nuevo tema: ¿Qué es poner óbice, para Agustín? Nos lo va a aclarar con una comparación entre el adulto y el infante. Citamos el texto en lo tocante a nuestro argumento, aunque lo hemos citado ya ampliamente antes:

"Hoc qui non credit et fieri non posse arbitratur, profecto infidelis est, etsi habeat fidei sacramentum; longeque melior est illo parvulus, qui

57 En la controversia donatista estos son los términos más usados en sus obras y en ocasiones aparecen también en otros escritos del tiempo. Cfr. C. litt. Petil. I, 23, 25, PL. 43, 247; C. Epist. Parmen. II, 11, 24, PL. 43, 68; De Bapt. c. Donat. I, 12, 18, PL. 43, 119; I, 11, 15-16, col. 118; II, 10, 13, col. 144; V, 8 , 9, col. 181; C. Gaudent. I, 12, 13, PL. 43, 711; I, 17, 18, col. 714; In Jo. Evang. tr. 13, 15, PL. 35, 1500, etc. Para un examen de estos aspectos y de las implicaciones también en sacramentaria del corpere et corde, vid. la tesis de mi discípulo J. M. BERnARdo PANIAGUA, "Sunt in Ecclesia corpere sed non corde" en la controversia agustiniana con los donatistas. (Studium theologicum "Augustinianum", 1969), dactil. Roma, 91 pp. 
etiamsi fidem nondum habeat in cogitatione, non ei tamen obicem contrariae cogitationis opponit, unde sacramentum salubriter percipit" 58.

El'pensamiento no tiene posibilidad de equívoco: el adulto que no cree que el sacramento de la fe por la caridad de la Iglesia libra al infante de la condenación, es infiel, aunque tenga el sacramentum fidei. En cambio el párvulo es mejor que ese adulto, ya que no opone el óbice de un pensamiento contrario a esa fe. El óbice sería, pues, la infidelidad, es decir no cheer con fe adulta lo que la Iglesia enseña sobre el valor del sacramento visible, o como nos había dicho en otro texto, despreciar el sacramento visible, pues quien lo desprecia no puede ser santificado invisiblemente. $Y$ como el infante no opone ese pensamiento contrario, no desprecia el sacramento visible, por eso no tiene óbice y recibe el sacramento saludablemente. Esto nos explicaría la controversia donatista y también la pelagiana, en lo referente a los sacramentos.

Pero hagamos un breve paréntesis y reflexionemos sobre algunos datos de la teología posterior y hasta del dogma. En el Concilio de Trento se anatematizó a quien diga que los sacramentos no contienen la gracia que significan, o que no la confieren a quienes no ponen óbi$\mathrm{ce}^{59}$. Y además se añadió que la confieren ex operé operato ${ }^{60}$. Nos interesa el examen del problema del óbice -aut gratiam ipsam non pionentibus obicem non conferre- ¿. ¿Cómo han definido el óbice los teólogos? He aquí una definición comúnmente admitida: "Obex de quo agitur est dispositio animale repugnans infusioni gratiate, nemple voluntas habitualiter vel actualiter peccato mortali adhatenens" ${ }^{61}$. Y lo mismo se dirá hablando de la reviviscencia de los sacramentos, distinguiéndolo en óbice positivo y negativo ${ }^{62}$. Ante estos hechos la reflexión siente su propio embarazo. No poner óbice es no adherirse la voluntad habitual o actualmente a un pecado grave. $Y$ si la voluntad no está adherida a un pecado grave, está en gracia. Mas como confiere la gracia a quienes no tienen óbice, la confiere a los que ya la tienen y entonces el sacramento significaría que ya la tienen, aunque en el segundo miembro del anatema pa-

58 Epist. 98, 10, PL. 33, 364. Sería preciso tratar más detenidamente el tema de la "causalidad" para no recaer en interpretaciones "protestantes". Lo haremos en otra ocasión, ya que este estudio es largo.

59 DS 1606.

60 DS 1608.

61. Hemos tomado la definición a un manual clásico en la teología de nuestro siglo, A. TANQUEREY, De Deo sanotificante et remuneratere, seu de Gratia, de sacramentis et die novissimis. T. III, Desclée ed. 25, 1947, 258.

62 ID., o. c., 272. 
rezca condenarse esto. El sacramento no confiere la gracia a los que tienen óbice, pero tienen óbice porque no tienen la gracia —se oponen a la infusión de ella por la adhesión al pecado grave-y solamente carece de óbice aquel que tiene ya la gracia. Y al otro ¿quién se lo quita? ¿Qué hace, pues, el sacramento? Según el Concilio de Trento, conferir la gracia a los que ya la tienen y decir que si no la tienen, no se la confieren. Agustín, empero, había entendido el óbice de otra manera, que puede ayudarnos a interpretar sin estridencias un pensamiento muy posterior al suyo.

Volviendo no obstante al tema abandonado, no tenemos por qué extrañarnos de la doctrina agustiniana. Está continuando su método teológico del crede ut intelligas. La fe es un supuesto fundamental y fundamentante para la vida cristiana y en él se coloca para entender lo sacramental. No le interesa de momento explicar el misterio de la producción o confección de la gracia, sino la significación y la inteligencia de unos efectos, que se traslucen en los sacramentos visibles con una santificación visible, signo de la invisible. La realidad de que el sacramento es signo, no se pone en duda, se admite por la fe. Ahora se trata de comprender el signo espiritualmente, de entenderlo y de vivirlo.

$\mathrm{Si}$ hacemos un breve parangón con lo natural, todo nos parece claro en agustiniano:

Creación-Dios

Impresión de la verdad

Tangi a veritate

Conscius de veritate ............

Expressio et illuminatio

\section{Recreación-Cristo}

Sacramentum fidei.

Percipere sacramentum.

Annuere mente rem ipsam, id est fidem.

Intellectus fidei $=$ spiritualiter.

Los pasos están bien definidos. El sacramento se entiende porque significa algo, la fe en el caso del bautismo. ¿La produce? Agustín no contesta a esta pregunta. Su respuesta sería: el niño tiene la fe - habet fidem-, pero no adulta -mon in voluntate credentis-, es decir tiene el sacramentum fidei y por él se dice que tiene la fe y cree, pues credere nihil est aliud quam fidem habere.

Ahora bien, la santificación visible sería el efecto de los sacramentos visibles por mediación de los ministros, y esa santificación visible sería el percipere sacramentum rei, el hecho de la recepción del sacramento. $\mathrm{Y}$ a esto se llama tener la realidad que significa. La santificación visible no es, por tanto, nada especial. El sacramentum rei supone la realidad 
de que es sacramento y llama a la toma de conciencia de la misma, a su inteligencia, a su participación personal, vital. Preguntar en agustiniano por la causalidad tendrá un sentido particular. Basta decir que significan. Los sacramentios, para san Agustín serian causa de la santificación visible —-serían la misma santificación visible-, y significan la santificación invisible, a cuya inteligencia y actuación vital llaman.

En el adulto, antes de la percepción del sacramento, se requiere la disposición que es la santificación invisible por medio de la gracia del Espíritu Santo, y no despreciar el sacramento visible, pues se haría infiel y por tanto incapaz de aquella santificación. Vendría luego la percepción del sacramento que es la santificación visible y significa la invisible, por la que es provechoso $\longrightarrow$ prodest y en la que radica todo su fruto y utilidad. Y el sacramento como signo es expresión y llamada a la vivencia de lo significado - admonición-, efectuándose esto mediante la inteligencia espiritual de lo significado visiblemente en el signo.

Camelat, en un breve, pero interesante artículo, intentando "esquematizar a grandes rasgos lo que podría ser una teología agustiniana de los sacramentos" escribe, luego de ver el catecumenado y la profesión de fe que se exige: "El bautismo es, pues, sacramento de la fe, puesto que comporta necesariamente esta profesión de fe en la enseñanza recibida en la catequesis, pero más todavía porque, signaculum fidei, el bautismo lleva esta fe a su perfección, permitiendo al neófito abrirse al misterio, acogerlo y dejarse penetrar por él. Agustín emplea de buen grado aquí el verbo imbuere que acabamos de encontrar, y que no expresa solamente que el catecúmeno debe recibir un sacramento, sino que debe dejarse penetrar y como impregnar por el misterio mismo" 63. Entendido en este ambiente general del espíritu agustiniano no ofrece dificultades: el bautismo le permite abrirse al misterio, pero le obliga a irlo entendiendo, a la inteligencia y a la vivencia, signándolo de ese modo. Aparece también claro en el parangón con la eucaristía, tratando del intellectus spiritualis y del spiritualiter intelligere "64. "Los sacramentos son así llamados - concluye- porque se ve una cosa, pero se comprende otra. Aliud videtur, aliud intelligitur (Serm. 272 PL. 38, 1248; cf. In Joann. tr. 26, i PL. 35, r6rr); este intellectus, por el que se puede,

63 Th. Camelor, "Sacramentum fidei": Augustinus Magistex II, Paris $1954,892$.

64 ID., art. cit., 893. 
más allá de la species corplonalis, percibir y gustar el fructus spiritualis, es la inteligencia de la $\mathrm{fe}{ }^{65}$.

El sacramento visible inicia en el misterio y por él se penetra en la realidad que significa para llegar a la inteligencia de la misma. Y el proceso es comprensible en la teoría general agustiniana que hemos expuesto desde el principio de estas páginas. Se trata de una perspectiva de fe e inteligencia, no de causalidad. $Y$ por la fe en la realidad que significa el sacramento recibido se llega ahondando a la inteligencia. El misterio de la causalidad queda intacto y sale de las manos de Agustín sin explicación de momento. No se crea, empero, que la fe de quien lo recibe produce el efecto del sacramento y que quien no la tiene, permanece sin el efecto del sacramento. Una cosa parece cierta en cuanto hemos expuesto, a saber: que la santificación visible puede existir - existe de hecho- sin esa fe -adesse-, porque el sacramento lo ha recibido, pero no aprovecha - non prodest-, pues le falta, por ese mismo hecho, la santificación invisible. La gracia invisible de que el sacramento es signo, no pende de la fe del que recibe ni del que administra el sacramento, sino que es Cristo y su Espíritu los dadores de esa gracia invisible y esto solamente pide del sujeto: que no oponga un pensamiento contrario. En el parangón que hemos insinuado, las dos santificaciones parecen diferentes y los instrumentos en ellas usados son distintos. Los conceptos de causa final, eficiente, meritoria, instrumental, formal no había hecho su aparición en el horizonte de Agustín y no tenemos por qué obligarle a pasar por esas estrecheces. Ha entendido el sacramento en su autenticidad de signo que es invitación y llamada a la comprensión o inteligencia vivida de lo significado, es decir a la toma de conciencia de lo invisible, a hacerse adulto en su vida sacramental.

Al llegar aquí, podemos seguir preguntando: ¿Qué relación existe entre ese doble elemento que hemos analizado, lo visible y lo invisible? ¿Existe una relación de causalidad, o solamente de signifficación o manifestación? En otros términos, ¿lo visible es causa de lo invisible, o más bien lo invisible exige en el hombre lo visible? En agustiniano, dada su trayectoria mental y sus aplicaciones a los diversos temas, tendríamos que decir que se camina de arriba abajo, y no de abajo arriba, o sea se parte de la existencia de lo invisible del que lo visible no será más que manifestación y admonición, y luego por lo visible se asciende nueva-

ID., art. cit., 894. 
mente, con consciencia plena, refleja, adulta, a lo invisible. En sacramentaria no podía ser de otro modo, si quería ser lógico con su pensamiento. Se parte de la existencila die la santificación invisible $\rightarrow$ no se explica el cómo, se muestra solamente en los textos- y de aquí se pasa al sacramento visible, cuyp diesprecio haría implosible aquélla, tomando pie de éste pana llegar a la inteligiencia espiritual de la santificación invisible, que en términos modernos diríamos para una toma de conciencia que conduce a la adultez y madurez en la vida cristiana. No obstante, Agustín es consecuente consigo mismo: para la admisión del misterio de lo invisible exige fe y un pensamiento no contrario a la enseñanza sobre el efecto del sacramento, que esto sería poner óbice. Sin embargo, la santificación invisible puede existir sin el sacramento visible, y aprovecha también; en cambio la santificación visible que es la recepción del sacramento puede también existir sin la santificación invisible, pero no aprovecha, no sirve. Esto significa que, en la actual economía, el sacramento visible es la prueba manifestativa de que ha aceptado la santificación invisible, que es gracia $\rightarrow$ y por tanto gratuita, sin méritosy se compromete a actualizarla, al tomar conciencia por medio de él de la necesidad de vivirla ${ }^{66}$.

INTENTOS DE DEFINICIÓN DE SACRAMENTO.

Añadiremos todavía cuanto Agustín nos ofrece más directamente, aunque sea de modo incidental, en torno al concepto de sacramento. Para comprenderlo mejor citemos el texto con el contexto:

"Nec illorum ergo sacrificiorum egebat Deus, nec cujusquam eget unquam, sed rerum divinitus impartitarum, vel imbuendo virtutibus animo, vel aeternae saluti adipiscendae, quaedam signa sunt, quorum celebratione atque functione, non Deo, sed nobis utilia pietatis officia exercentur. Nimis longum est convenienter disputare de varietate signorum, quae cum ad res divinas pertinent, sacramenta appellantur..." 67.

La definición, pues, que aquí nos da, sería ésta: signa quae ad res divinas plertinent, sacramenta appellantur. La amplitud de la misma es evidente y no hay sentido estricto aquí. Antes de analizar las palabras

66 Agustín admite la necesidad del sacramento, porque el sujeto, al recibirlo, prueba que se somete a la voluntad de Dios, manifestando así que la gracia está presente y actúa ya en él.

67 Epist. 138, 1, 6-7, PL. 33, 627. 
constitutivas, hagamos unas anotaciones, teniendo en cuenta el contexto, ya que esto nos desbrozará el camino para la inteligencia de 11 definición. Dios no necesita de los sacrificios - se trata de sacrificios visibles, internos o externos-, y nunca ha necesitado ni necesitará de ellos. Y siguiendo el pensamiento, agregaríamos que Dios no necesita de sacramentos ni los ha necesitado nunca. Los sacramentos como los sacrificios y su celebración son útiles para los hombres, no para Dios. Toda la utilidad radica en su ser de signos y son signos de las cosas divinamente impartidas, o para imbuir el ánimo de virtudes o para lograr la salvación eterna.

La explicación más clara de este hecho la tenemos sin duda en La Ciudad de Dios, donde trata el mismo tema, es decir la mutabilidad de los signos y habla a su vez del sacrificio. Dice así :

\footnotetext{
"Non solum igitur pecore, sed qualibet alia re corruptibili atque terrena, sed ne ipsa quidem iustitia hominis Deus egere credendus est, totumque quod recte colitur Deus, homini prodesse, non Deo. Neque enim fonti se quisquam dixerit profuisse, si biberit; aut luci, si viderit. Nec quod ab antiquis patribus talia sacrificia facta sunt in victimis pecorum, quae nunc Dei populus legit, non facit, aliud intelligendum est, nisi rebus illis eas res fuisse significatas, quae aguntur in nobis, ad hoc ut inhaereamus Deo, et ad eumdem finem proximo consulamus. Sacrificium ergo visibile invisibilis sacrificii sacramentum, id est sacrum signum est... Ac per hoc ubi scriptum est, Misericordiam volo quam sacrificium; nihil aliud quam sacrificio sacrificium praelatum oportet intelligi: quoniam illud quod ab omnibus appellatur sacrificium, signum est veri sacrificii. Porro autem misericordia verum sacrificium est: unde dictum est quod paulo ante commemoravi, Talibus enim sacrificiis placetur. Deo. Quaecumque igitur in ministerio tabernaculi sive templi multis modis de sacrificiis leguntur divinitus esse praecepta, ad dilectionem Dei et proximi significandám referuntur" 68 .
}

El contexto es el mismo que en el texto precedente y el contenido idéntico. Dios no necesita ni siquiera de la justicia del hombre, no necesita ni de su misericordia. El sacrificio visible es sacramento del invisible, y dice referencia a Dios, implica un propter Deum. Al definirnos el sacrificio nos percatamos de que el sacrificio es también una realidad divina. He aquí sus palabras:

"Proinde verum sacrificium est omne opus, quod agitur, ut sancta societate inhaereamus Deo, relatum scilicet ad illum finem boni, quo vera-

68 De civ. Dei X, 5, PL. 41, 282. 
citer beati esse possimus. Unde et ipsa misericordia qua homini subvenitur, si propter Deum non fit, non est sacrificium. Etsi enim ab homine fit vel offertur, tamen sacrificium res divina est: ita ut hoc quoque vocabulo id Latini veteres appellaverint..." 69.

La primera pregunta que viene a nuestra mente es ésta: ¿Por qué el sacrificio es res divina? En la respuesta hallaremos la clave para nuestro tema, dado que también aquí se da un ministro, que es el hombre. Mas, a pesar de que quien lo ofrece es el hombre, el sacrificio es cosa divina. Y lo es por la referencia o relación a Dios, ya que si no lleva esa relación a Dios, no es sacrificio. Lo constituye, pues, tal el propter Deum. Y eso mismo lo distingue de los falsos sacrificios. Lo que comúnmente se llama sacrificio es signo del verdadero sacrificio. Lo externo es lo visible, el signo de aquellas realidades, quaxe aguntur in nabis. De donde se sigue que al decir: el sacrificio visible es sacramento, es decir signo sagrado, del sacrificio invisible, quiere significar que el sacrificio visible, c sea el ofrecido en víctimas u otras cosas externas es sacramento o signo sagrado del sacrificio invisible, es decir de aquellas cosas quae aguntur in nobis, ad hoc ut inhatereamus Deb, et ad hunc finem proximo consulamus, significadas por las anteriores. Aquí las significan también, pero no se dice tampoco que las causen.

En textos paralelos tenemos las dos definiciones de sacramento que se equivalen: signa quae ad res divinas pertinent, sacramenta appellantur, y además: sacrificium visibile invisibilis sacrificii sacramentum, id est signum sacrum. Como el sacrificio es res divina, todo está ya claro: sagrado significa igual que ad res divinas pertinent. Ahora bien, si la realidad divina aparecía justamente en la referencia a Dios, resulta que ad res divinas pertinent significaría sencillamente "lo que dice relación a Dios, o se hace por Dios".

69 Id. X, 6, PL. 41, 283-284. Y el texto continuaba: "Cum igitur vera sacrificia opera sint misericordiae, sive in nos ipsos, sive in proximos, quae referuntur ad Deum; opera vero misericordiae non ob aliud fiunt, nisi ut a miseria liberemur, ac per hoc ut beati simus; quod non fit, nisi bono illo, de quo dictum est, Mihi autem adhaerere Deo bonum est: profecto efficitur, ut tota ipsa redempta civitas, hoc est congregatio societasque sanctorum, universale sacrificium offeratur Deo per sacerdotem magnum qui etiam se ipsum obtulit in passione pro nobis, ut tanti capitis corpus essemus, secundum formam servi. Hanc enim obtulit, in hac oblatus est; quia secundum hanc mediator est, in hac sacerdos, in hac sacrificium... Hoc est sacrificium christianorum: Multi unum corpus in Christo. Quod etiam Sacramento altaris fidelibus noto frequentat Ecclesia, ubi ei demonstratur, quod in ea re quam offert, ipsa offeratur". Nos gustaría apurar más el término "sacrificium" para definir la teología agustiniana propiamente sacramentaria. Pero no podemos detenernos. 
Examinemos, no obstante, el concepto que Agustín tiene de signo y de res. La distinción nos la ofrece casi en sistema con los términos siguientes, que citamos en amplio para seguir el argumento:

\begin{abstract}
"Omnis doctrina vel rerum est vel signorum, sed res per signa discuntur. Proprie autem nunc res appellavi, quae non ad significandum aliquid adhibentur, sicuti est lignum, lapis, pecus, atque hujusmodi caetera. Sed non illud lignum quod in aquas amaras Moyses mississe legimus, ut amaritudine carerent; neque ille lapis quem Jacob sibi ad caput posuerat; neque illud pecus quod pro filio immolavit Abraham. Hae namque ita res sunt, ut aliarum etiam signa sint rerum. Sunt autem alia signa quorum omnis usus in significando est, sicuti sunt verba. Nemo enim utitur verbis, nisi aliquid significandi gratia. Ex quo intelligitur quod appellem signa: res eas videlicet quae ad significandum aliquid adhibentur. Quamobrem omne signum etiam res aliqua est; quod enim nulla res est, omnino nihil est: non autem omnis res etiam signum est" 70.
\end{abstract}

Agustín ya da por supuesto que la palabra es un signo propiamente dicho y que toda su esencia consiste en significar algo y para eso se usa. En cambio aquí al tratar de definir la res y el signum, va a manifestarnos que el signum es una realidad usada plana significar algo. Serán, pues, cosas o personas o acontecimientos que se utilizan para a través de ellos significar algo. $\mathrm{Y}$ así nos dirá aquí todavía que considera en la res quod sunt, dejando aparte el quod aliud praeter seipsam significat. En esto último sería ya signo y no sólo sería res, habiendo definido también por eso el signo como res ${ }^{71}$. Y nos ofrece la ya clásica definición de signo, haciendo nuevamente referencia a la res, dada la división que antes había hecho:

“...vicissim de signis disserens hoc dico, ne quis in eis attendat quod sunt, sed potius quod signa sunt, id est, quod significant. Signum est enim. res, praeter speciem quam ingerit sensibus, aliud aliquid ex se faciens in cogitationem venire: sicut vestigio viso, transisse animal cujus vestigium est, cogitamus; et fumo viso, ignem subesse cognoscimus; et tuba sonante, milites vel progredi se, vel regredi, et si quid aliud pugna postulat oportere noverunt" 72 .

Entre los signos considera la palabra y estudia la diversidad de los mismos, hablando de signos naturales y de signos dados, de signos propios y de signos traslaticios. Todo esto lo aplica en principio a la inter-

70 De doctr. christ. I, 2, 2, PL. 34, 19-20.

71 Id. II, 1, 1-2, PL. 34, 35-37.

72 Id. II, 1, 1, PL. 34, 35. 
pretación de la Escritura, dando las reglas. El consentimiento de quien observa es esencial para muchos signos y de ello depende su interpretación, ya que los signos dados son "quase sibi quaeque viventia invicem dant ad demonstrandios, quantum possunt, motus animi sui, vel sensa, aut intellecta quaelibet" 73. Y cuando hay signos divinitus instituta, el hombre no los constituye, sino que los descubre y aprecia su significación ${ }^{74}$. Si para los signos dados el consentimiento es esencial, para los sacramentos lo sería la fe y entonces todo seguiría el mismo proceso.

$\mathrm{Si}$ penetramos en la esencia íntima del signo, tal como la entiende Agustín, topamos de inmediato con dos elementos: uno visible y otro invisible - la especie que está ante los sentidos, y cuanto hace venir al pensamiento-. En esto radica su profundidad, en eso que podríamos llamar causalidad significativa, que requiere siempre una persona, un hombre, con un consentimiento en lo significado por el signo, y en lo sacramental, con la fe en lo mismo. Es lo que en otras partes había dicho y repetirá : aliud videtur, aliud intelligitur ${ }^{75}$. El signo usa de la especie como medio e instrumento para hacer venir al pensamiento, a la consciencia, otra realidad, es decir la realidad que quería significar por medio del signo. En este aspecto, todo signo es infalible para el adulto que lo conoce y produce pior lo mismo su efectio, ya que la realidad que sirve de signo tiene dos caras, apareciendo una directamente y llamando y suscitando la otra. Alguno dirá que nos detenemos en la filosofía del signo, en lugar de tratar la teología del signo sacramental. Queremos en efecto asentar los fundamentos filosóficos, ya que no siempre se hace así.

Tenemos ya, pues, por una parte, lo que es el signo y cuanto comporta. Y sabemos también lo que significa la res, es decir la realidad que no se aplica a significar algo más, sino que en ella se considera sólo su ser. El signo es, por tanto, relativo y la realidad en cierto modo absoluta. Todo signo es, en consecuencia, medio para traer a la mente, al pensamiento, algo, lo que se quería significar por él.

Podemos, tras estas explicaciones, entrar en la inteligencia del sacramento o mejor de la definición del mismo, siguiendo el pensamiento agustiniano. Se llaman sacramentos los signos, es decir aquella realidad que además de la especie que pone ante los sentidos, hace venir ex se

73 Id. II, 2, 3, PL. 34, 37 .

74 Id. II, 27, 41, PL. 34, 55.

75 Serm. 272, PL. 38, 1248; In Jo. Evang. tr. 26, 11, PL. 35, 1611. 
a la consciencia otra cosa, y esos signos dicen relación a las cosas divinas. Los sacramentos son, pues, signos sagrados por decir relación a las cosas divinas, y su acción se concreta en unirnos a Dios. Definiéndolos, habida cuenta de todo esto, diríamos que los sacramentos son signos sagrados, que, mostrandlo inmediatamente su aptariencia, haden venir ex se a la consciencia otra realidad, que es la espiritual, referente a cosas divinas. Como en todo signo, la otra realidad ya existe, pero no se había tomado conciencia de ella y esto se hace mediante el signo.

Morel ha examinado ampliamente algunas cuestiones y ha intentado un acercamiento a las nociones de signum, de res y de pertinere, haciendo una serie de aplicaciones casi en plan cabalístico. Las conclusiones tienen su interés y quedarían reducidas en aquellos tres apartados suyos: “a) El sacramento es un signo al que el pensamiento del creyente reconoce una relación con las "cosas divinas". Dicho de otro modo: $E l$ sacramento es un signo relativo". Y hace la relación a la realidad misma de Dios, al conocimiento objetivo que la revelación da de Dios, al misterio del que la fe tiene la inteligencia, a los sucesos de Dios, al Reino de Dios, a la felicidad de los elegidos; "b) El sacramento es un signo, cuya Institución, significación y fin procieden de la soberana competencia de Dios. Tomando el verbo emanar en un sentido jurídico, diremos que: El sacramento es un signo que emana". Y hace las mismas combinaciones más o menos que en el párrafo anterior; “c) El sacramento es un signo que comunica lo que significa. Confina al misterio al que es relativo y del que emana. Es un medio de gracia. Brevemente: El sacramento es un signo que logra" "76. Y luego escribe, una vez terminado este análisis: 'Las 'cosas divinas', hemos dicho, especifican el sacramento por relación al signo en general : inversamente, la noción de signo debe permitir especificar el sacramento por relación a las "cosas divinas que enseña la teología. Desde este punto de vista, el estudio de la noción de signo es de una importancia capital, no solamente para la inteligencia de los ritos sacramentales, sino también de la teología en su conjunto" ${ }^{77}$. E insistiendo sobre la noción de signo, concluye con estas palabras: "San Agustín mismo ordenándolo todo a una significación trascendente, lo ha tomado según sus acepciones usuales: el signum sacramental es el indicio,

76 B. Morel, Le signe sacré. Essai sur le sacrement comme signe et information de Dieu, Paris 1959, 35.

77 ID., o. c., 36. En otra ocasión estudiaremos más detenidamente el signo sacramental desde la teología de Agustín. 
la manifestación de algo oculto; es un estandarte, un símbolo de la vida cristiana (esto es verdad sobre todo del bautismo y de la eucaristía); es una huella indeleble (bautismo, matrimonio y ordenación); es un sello de Dios sobre su palabra (todos los sacramentos) o sobre los fieles (bautismo). El signum latino era ya una noción equívoca, cuyas diversas nociones no entraban de la misma manera en la definición de los sacramentos en particular. Si el sacramento del bautismo no es lo mismo que el de la eucaristía, es porque el bautismo y la eucaristía no son signos por el mismo título" 78. La conclusión que el autor destila es que Agustín ha hecho progresar mucho el tratado de los sacramentos, pero sus conceptos eran todavía imprecisos, abarcando demasiado en sus concepciones.

San Agustín, sin embargo, no se ha desviado de la línea que venimos trazando en el análisis de textos y de pensamiento. Nos plantea muchas cuestiones pero no queremos hacerle preguntas todavía. Seguiremos examinando otros acercamientos al mismo tema. Quizá al final habría que hacer virar un poco también su concepción de la gracia, o mejor, la interpretación que se ha hecho de su concepción. Los sacramentos son, por tanto, signos que dicen relación a las cosas divinas, y como todo signo muestra una cara y hace aparecer otra a la mente, el sacramento muestra la cara visible y hace ex se aparecer en la consciencia -sería producir en cierto modo- la cosa divina a que dice relación.

EXAMEN DE OTROS TEXTOS.

Dada la trayectoria de este pensamiento agustiniano que parece constante en su doctrina, no debiera ofrecernos dificultades de interpretación el texto que ha pasado a todos los manuales de teología. Al probar la tesis de que "todos los sacramentos de la Nueva Ley, considerados en su elemento sensible, constan esencialmente de cosas y de palabras, que se llaman convenientemente materia y forma de los sacramentos", se aduce el texto de Agustín, "qui clare distinguit elementum et verbum" " 9 . Sin embargo, la interpretación entre los autores, como comprobaremos, ha sido muy variada. Citemos primeramente el texto para que no hay a lugar a confusiones:

78 ID., o. c., 37.

79 A. TANQUEReY, o. c., 249. 
"Jam vos mundi estis propter. verbum quod locutus sum vobis. Quare non ait, mundi estis proptc $r$ baptismum quo loti estis, sed ait, propter verbum quod locutus sum vobis, nisi quia et in aqua verbum mundat? Detrahe verbum, et quid est aqua nisi aqua? Accedit verbum ad elementum et fit sacramentum, etiam ipsum tanquam visibile verbum. Nam et hoc utique dixerat, quando pedes discipulis lavit: Qui lotus est, non indiget nisi ut pedes lavet, sed est mundus totus (Jo 13, 10). Unde ista tanta virtus aquae, ut corpus tangat et cor abluat, nisi faciente verbo: non quia dicitur, sed quia creditur? Nam et in ipso verbo aliud est sonus transiens, aliud virtus manens. Hoc est verbum fidei quod praedicamus, ait Apostolus, quia si confesisus fueris in ore tuo quia Dominus est Jesus et credideris in corde tuo quia Deus illum suscitavit a mortuis, salvus eris. Corde enim creditur ad justitiam, ore autem confessio fit ad salutem (Ro 10, 8-10). Unde in Actibus Apostolorum legitur, Fide mundans corda eorum (Act. 15, 9): et in Epistola sua Beatus Petrus, Sic et vos, inquit, Baptisma salvos facit: non carnis depositio sordium, sed conscientiae bonae interrogatio (1 Ptr. 3, 21). Hoc est verbum fidei quod praedicamus: quo sine dubio ut mundare possit, consecratur et Baptismus. Christus quippe nobiscum vitis, cum Patre agricola, dilexit Ecclesiam et tradidit seipsum pro, ea. Lege Apostolum, et vide quid adjungat, Ut eam sanctificaret, inquit, mundans eam lavacro aquae in verbe (Eph. 5, 25-26). Mundatio igitur nequaquam fluxo et labili tribueretur elemento, nisi adderetur in verbo. Hoc verbum fidei tantum valet in Ecclesia Dei ut per ipsum credentem, offerentem, benedicentem, tingentem, etiam tantillum mundet infantem..." 80 .

El texto presenta más de una dificultad y los autores la han visto realmente. Moriones ${ }^{81}$ expone las diversas opiniones sobre la interpretación de verbum, sea como invocación de la Santísima Trinidad o forma del bautismo, sea como la previa bendición del agua destinada al bautismo. Los antiguos, según él, están por la primera sentencia, por

80 In Jo. Evang. tr. 80, 3, PL. 35, 1840. En el n. 2, col. 1839-1840 se decía: "Denique cum de Patre itaquam de agricola dixisset quod infructuosos palmites tollat, fructuosos autem purget ut plus afferant fructum; continuo etiam seipsum mundatorem ostendens, Jam vos, inquit, mundi estis propter sermonem quem locutus sum vobis. Ecce et ipse munidator est palmitum, quod est agricolae, non vitis officium: qui etiam palmites operarios suos fecit. Nam etsi non dant incrementum, impendunt tamen aliquod adjumentum; sed non de suo: Quia sine me, inquit, nihil potestis facere. Audi etiam ipsos confitentes: Quid autem est

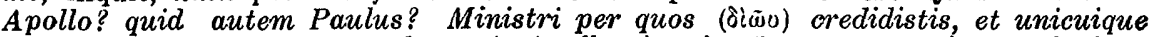
sicut Dominus dedit. Ego plantavi, Apelle rigavit. Eit hoc ergo sicut unicuigue Dominus dedit: non itaque de suo. Jamvero quod sequitur, sed Deus incrementum dedit (1 Cor. 3, 5-7); non per illos, sed per seipsum fecit: excedit hoc humanam humilitatem, excedit angelicam sublimitatem, nec omnino pertinet nisi . ad agricolam Trinitatem. Jam vos mundi estis, mundi scilicet atque mundandi. Neque enim nisi mundi essent, fructum ferre potuissent; et tamen omnem qui fert fructum, purgat agricola, ut fructum plus afferat. Fert fructum, quia mundus est; atque ut plus afferat, purgatur adhuc. Quis enim est in hac vita sic mundus, ut non sit magis magisque mundandus?...". 551-552.

81 F. MoRIONES, Enchiridion theologicum sancti Augustini, Madrid 1961, 
decir que es la forma del sacramento y con él están algunos modernos como Gendreau, aduciendo sus razones. Ctros opinan que esas palabras se amplían a la bendición del agua, y él mismo confiesa que esta segunda opinión no carece de probabilidad. Cree más probable la primera sentencia, respondiendo a las posibles objeciones e interpretando el texto de este modo: "Verba 'non quia dicitur, sed quia creditur', videntur intelligenda de dispositionibus requisitis ut effectus gratiae baptismalis abtineatur, quamvis validitas baptismi absque illis salva maneat" ${ }^{82}$. Por su parte, Camelot, tras el análisis del sacramentum fidei, escribe: "Si el bautismo es sacramento de la fe, porque comporta la profesión de fe del catecúmeno, se verá en qué sentido es preciso comprender el famoso texto de In Joann. tr. LXXX, 3; PL. 35, I840: "Accedit verbum ad elementum et fit sacramentum" (...) non quia dicitur, sed quia creditur". El verbum, es sin duda la fórmula sacramental, tomada a las palabras del Señor mismo, "sanctitas sacramenti verbis evangelicis consecrata", pero es también - porque los dos sentidos no se excluyenla fórmula por la que el neófito expresa su fe, y por la que se abre a la res espiritual que viene a él en el sacramento. "Aliud videtur, aliud intelligitur... sed quia creditur" ${ }^{83}$. El verbum indicaría, pues, dos cosas la forma del sacramento y también la profesión de fe que hace el catecúmeno antes de bautizarse.

¿Qué es el verbum, y el verbum fidei que se añade, y verbum quod locutus sum vobis? El incremento lo da Dios, non per illos, sed per seipsum facit, no por los operarios, sino por sí mismo. Esto es interesante. Los operarios, aunque no dan el incremento, ofrecen cierta ayuda, pero el limpiador pleno es el agricultor, no los sarmientos, y él es también limpiador de éstos. $\mathrm{Y}$ ese agricultor es la Trinidad, y en consecuencia de ella depende la limpieza de los sarmientos, haciendo a éstos operarios suyos, quedándoles comisionada solamente una cierta ayuda -aliquod adjumentum-.

Con esto por delante, Agustín pasa a exponer el texto del Evangelio: Jam vos mundi estis pnopter vierbum quod locutus sum vobis, y como que se extraña de que no se diga que están purificados o limpios por o en virtud del bautismo, con que fueron lavados, sino en virtud o

$82 \quad I b$.

83 Th. CAmelot, art. cit., 894. No queremos decir con esto que San Agustín lo atribuya todo a la "palabra". 
por la palabra que El les habló. En el contexto aquí comienza toda la profundidad y la dificultad con la grandeza que se ha visto siempre en este texto: Están limpios en virtud o gracias a la palabra. Tiene que dar una respuesta satisfactoria a su auditorio, que sin duda está también maravillado del texto evangélico, ya que también comprende que es el bautismo el que los ha purificado. Y si es el bautismo, según el sentir común del pueblo fiel, ¿cómo el Evangelio dice que están limpios por la palabra que El les ha hablado? La respuesta va en la misma pregunta: En el agua limpia también la palabra, ya que, suprimida la palabra, el agua queda reducida a agua. La purificación, pues, diríamos con el Santo, se debe a la palabra. Pero una vez más nos asaltan los interrogantes: ¿Se debe a la palabria sola, o a la palabra y al agua? En el contexto agua sería paralelo de baptismus quo loti estis y los apóstoles estaban limpios no por el agua, sino por la palabra. La purificación es efecto de la palabra y esa palabra se acerca al elemento, en este caso el agua, y se hace sacramento, siendo éste como una palabra visible. La palabra produce el efecto espiritual y se visibiliza al pronunciarse sobre el elemento, tornándose por ese hecho sacramento, es decir signo sensible de lo ya producido, pues cree que ya se ha producido. Por eso puede preguntarse el Santo a renglón seguido: ¿De dónde le viene tal virtud al agua, de tocar el cuerpo y limpiar el corazón, sino gracias a la palabra y por obra de ella -faciente verbo-, no por pronunciarla - non quia dicitur-, sino por creerla -sed quia creditur-? $\mathrm{Y}$ añade: Cuidado, que en la palabra una cosa es el sonus transiens, y otra, la virtus maniens. No ha cambiado el pensamiento, si recordamos cuanto hemos venido exponiendo. La palabra pnonunciadla hace o se hace sacramiento, la palabra creída produce la purificación que significa el sacramento.

$\mathrm{Y}$ ¿qué es esa palabra? El Santo ha juntado a ese texto de San Juan, otra serie de ellos, paralelos, a su juicio, al menos para probar lo que pretendía en su homilía. Cita Rom. 10, 8-1o, Act. 15, 9, l Petr. 3, 2I, Eph. 5, 25-26 y en todos ellos nos manifiesta la purificación por la fe y casi diríamos, la salvación por el bautismo, que es consagrado por la fe para que pueda purificar. En el bautismo y sin él, la que purifica es la fe, es el verbum fidei y el bautismo solamente purifica en virtud de la fe que esa es la palabra, no en su sentido transitorio, sino permanente, no al ser pronunciada, sino al ser creída. Como en otros apartados hemos concluído, también aquí podríamos decir que la palabra de fe -verbum fidei- puede existir sin el bautismo y aprovechar; en cam- 
bio el bautismo puede existir sin la fe, pero no aprovecha. El doble elemento, lo visible y lo invisible, está claro una vez más.

El pensamiento final nos lo expresa así : Cristo, vid entre sarmientos, agricultor con el Padre, amó a su Iglesia y se entregó por ella. $\mathrm{Y}$ es limpiador de los sarmientos por ser agricultor con el Padre, no por ser vid con nosotros, pues eso est agricolale, non vitis officium, haciendo a los sarmientos operarios suyos. Y el Apóstol, después de haber dicho que Cristo amó a su Iglesia y se entregó por ella, agrega: Ut eam sanctificaret, mundans eam lavacro aquate in verbo. "La purificación en modo alguno la atribuiría al lábil y flúido elemento, sino añadiera in verbo, en la palabra". El valor no se da a la totalidad -verbum et elementum-, sino al verbum, en virtud de la cual se atribuye al agua la purificación. No es el conjunto, agua y palabra, lo que vale en la Iglesia de Dios, sino la palabra, porque dice todavía: "Este verbum fidei vale tanto en la Iglesia de Dios que en virtud de ella o por ella limpia al creyente, al oferente, al que bendice, al que toca, aunque sea un tierno infante, que aún no puede creer con el corazón para justificarse ni hacer la confesión de boca para salvarse". El per merece toda consideración, sin olvidar tampoco que antes había dicho que la purificación la hace per seipsum, non per alios. No se debe la purificación al agua, sino a la Trinidad $\longrightarrow$ ad agricolam Trinitatem-, al verbum fidei, y a él non quia dicitur, sed quia creditur. A través de todo esto, la contraposición clarea de este modo: mundi estis propter verbum quod locutus sum vobis, ait - non ait, mundi estis propter baptismum quo loti estis. $\mathrm{Y}$ esto lo ha dicho así, agrega Agustín, porque también en el agua la que purifica es la palabra.

Los interrogantes se acumulan todavía: ¿Qué es esa palabra: es la forma del sacramento, como se ha entendido en la teología posterior, o es más bien la bendición del agua por invocación de la Santísima Trinidad, o quizá la profesión de fe del bautizando, o es toda la doctrina de Cristo predicada a sus Apóstoles? ¿A qué se refiere Agustín? Los autores se dividen en la interpretación. Gendreau piensa que debe entenderse de la forma del sacramento, aduciendo una serie de razones, poco convincentes ${ }^{84}$. Moriones concluye, luego de exponer las opinio nes: "Si hic tantum textus consideretur, res quidem obscura est, et secunda sententia probabilitate non caret. Tamen, rationibus inspectis

84 J. J. Gendreau, Sancti Augustini dactrina de baptismo, Baltimore 1939. 
quas attulimus, prima sententia probabilior videtur. Argumentis vero secundae interpretationis responderi potest, quod quamvis magni momenti sit benedictio aquae baptismalis et professio fidei in baptizato, tamen Augustinus pro valido habet baptismum aqua non benedicta collatum, et etiam baptismum ab haeretico ministratum. Verba, 'non quia dicitur, sed quia creditur' videntur intelligenda de dispositionibus requisitis ut effectus gratiae baptismalis obtineatur, quamvis validitas baptismi absque illis salva maneat. Ita etiam Hocedez, H., La conception augustinienne du sacrement dans le tractatus 80 in Joannem. Recherches de science religieuse Io (1919), I-29, p. 28; M. ComeAu, Saint Augustin exégète du quatrième Evangile. Paris 1930, p. $345^{35}$.

Tengo la impresión de que se trasladan categorías posteriores al pensamiento agustiniano. No obstante, para cerrar el recuento, citemos a otro autor que se inclina a la segunda sentencia, sin excluir la primera. Dice así Tixeront: "Se ha visto en este texto la prueba de que san Agustín admitía que el rito sacramental mismo - por oposición a su res o virtus - se componía de dos elementos, una materia o gesto visible y las palabras: dando las palabras al gesto o a la materia su virtud santificadora. Y sin duda el texto de san Agustín no excluye esta explicación; pero es de creer que el autor no restringía a las solas palabras que acompañan la colación del rito $\rightarrow \mathrm{y}$ que nosotros llamamos la formala virtud santificadora del sacramento. Para él, como para san Ambrosio, lo que hace al agua capaz de purificar el corazón en el bautismo, es primeramente la bendición previa que ella recibe: "Quia baptismus, id est salutis aqua non est salutis, nisi Christi nomine consecrata, qui pro nobis sanguinem fudit, cruce ipsius aqua signatur" (Serm. 352, 3). La fórmula trinitaria tiene su parte en esta acción santificadora, pero no viene más que en segundo lugar. No es, pues, en modo alguno cierto que en el pasaje citado más arriba la palabra verbum designa y sobre todo designa únicamente la invocación de la Trinidad que acompaña la efusión bautismal ; puede designar también la bendición previa del agua, y aún puede designar la recitación sobre el símbolo hecha por el bautizado" ${ }^{86}$. A estas dos interpretaciones pueden reducirse los intentos de los autores.

¿No podría entenderse de otra manera ese uerbum fidei? Si nos

85 F. Moriones, o. c., 552, en nota.

86 J. TIXERONT, Histoire des dogmes dans lantiquité chrétienne. II. De saint Athanase à saint Augustin (318-430), Paris 1921, 398-399. 
atenemos a estas dos palabras que son las que están en juego en todo el contexto, hallaríamos quizá una correspondencia bastante fácil. Agustín habla en el texto del valor del verbum fidei en la Iglesia y dice correspondencia con otro texto que hemos examinado ya anteriormente. Tenemos, pues:

\begin{abstract}
"Hoc verbum fidei tantum valet in ecclesia Dei, ut per ipsum creidentem, offerentem, benedicentem, tingentem, etiam tantillum mundet infantem; quamvis nondum valentem corde credere ad justitiam, et ore confiteri ad salutem. Totum hoc fit per verbum..." 87 .
\end{abstract}

\begin{abstract}
"Hoc quamdiu non potest, valebit sacramentum ad ejus tutelam adversus contrarias potestates; et tantum valebit ut si ante rationis usum ex hac vita emigraverit per ipsum sacramentum commendante Ecclesiae charitate, ab illa condemnatione, quae per unum hominem intravit in mundum, christiano adjutorio liberetur" 88.
\end{abstract}

En el texto de la Carta, aunque en la cita no aparece el sacramentum fidei, sin embargo está presente continuamente, como hemos ya visto. Y entonces la correspondencia parece clara: verbum fidei = sacra mentum fidei. En uno y otro caso habla del niño que no ha llegado al uso de la razón y para quien el bautismo serviría contra las asechanzas del enemigo y le libraría de la condenación eterna. La palabra purifica quila creditur, pero al pronunciarla sobre el elemento se trueca en signo sensible de lo acaecido, siendo como una palabra visible, y distinguiéndose en ella el sonus transiens y la virtus manens, aquel como signo sensible de ésta. La purificación que es lo invisible se debe a la palabra, no al agua, y entonces esa palabra que es invisible, al pronunciarse sobre el elemento que es el agua, se hace sacramento - fit sacramentum, etiam ipsum tanquam visibile verbum-. No se dice que el sacramentum fit ex verbo et elemento, sino accedit verbum ad elementum et fit sacramientum, ¿tiene un sujeto ese fit? ¿Quién o qué se hace sacramento? ¿Qué tendríamos que preguntarnos: qué se hace sacramento, o de qué se hace el sacramento, para Agustín en este texto? La traducción ordinaria es la siguiente: "Se junta la palabra al elemento y se hace el sacramento". Y hasta se puede añadir con el P. Armas: "Aunque san Agustín no dio a la doctrina sobre la materia y forma de los sacramentos la perfección y precisión teológica de nuestros días, él fue quien propor-

87 In Jo. Evang. tr. 80, 3, PL. 35, 1840.

88 Epist. 98, 10, PL. 33, 364. 
cionó a los escolásticos la primera fórmula didáctica donde se ponen de relieve los dos elementos constitutivos del signo sagrado y santificador: Accedit verbum ad elementum et fit sacramentum. Es un texto clásico, invocado por los teólogos a porfía, cuando tratan de legitimar el hilemorfismo sacramentario" " ${ }^{89}$. Sin embargo, éstos no son más que prejuicios históricos que se han adicionado a un texto que podría prestarse a confirmar una doctrina ya construída. Pero jes esa la auténtica interpretación? En Agustín subsisten los dos elementos, lo visible y lo invisible, de que hemos hablado ya ampliamente y en nuestro caso no puede dudarse. Si pudiéramos penetrar más allá en el texto, tal vez definiéramos el alcance de esta sacramentaria incipiente, pero profunda. A través de los análisis hemos comprobado que Agustín comisiona la purificación a la palabra - propter verbum quod locutus sum vobis-y se trata en ello de una purificación interior, invisible, que se manifiesta en el bautismo, trocándose entonces aquella palabra en sacramento.

En el texto, pues, no se trataría de los elementos del sacramento, sino de algo que se hace sacramento: loti estis, non propter baptismum, sed propter verbum quod locutus sum vobis, quod verbum accedit ad elementum et fit sacramentum. "Estáis limpios —sería la traducción-, no por el bautismo, sino en virtud de la palabra que os he hablado, que se junta al elemento y se hace sacramento". El sujeto, por tanto, de fit sería verbum y lo sería también de accedit, yendo ambos unidos por la conjunción et en el texto. El verbum fidei se hace sacramentum fidei, siendo éste como una palabra visible, y por tanto, la otra es invisible.

Decir que las palabras non quia dicitur, sed quia creditur deben entenderse de las "disposiciones requeridas para lograr el efecto de la gracia bautismal, aunque quede a salvo sin ellas la validez del bautismo" es confirmarnos en nuestra interpretación. Porque si la fe es condición requerida para que el bautismo logre el efecto de la gracia bautismal, nos preguntaríamos si el bautismo produce algo o solamente significa la fe existente que se visibiliza al recibir el bautismo, se hace sacramento, es decir una especie de palabra visible. Todavía más: ¿Produce o logra su efecto por la fe, es decir gracias a ella y porque ya existe en el alma, o más bien gracias al bautismo y en virtud' de él? En nuestra línea de interpretación la secuencia sería ésta: el bautismo produciría la santificación exterior, visible, sería el sacramento de la fe, aunque la fe no

89 G. ARmas, La moral de San Agustín, Madrid 195'4, 866, nota 3. 
existiera en el corazón. Mas si esa fe existía —o si existe en estado latente como en el párvulo-, ese sacramentum fidei llama a la fe en el sujeto y le lleva a la toma de consciencia y a la realización de la misma -non repettet, sed intelliget-- En todo caso la purifioación sería obra de la Trinidad, de Cristo ut agricola, non ut vitis, que obraría por sí mismo - per seipsum-, propter verbum quod locutus sum vobis, y no propter baptismum quo loti estis, ni pier illos pialmites vel openarios que prestan aliquod adjumentum. Así se nos aparece el pensamiento agustiniano sin contorsiones, dada la contextura de los textos que hemos ido señalando.

Philips concluía una fuerte discusión con estas palabras: "Es preciso ahondar los textos. En las citas que aportáis: "accedit verbum ad elementum et fit sacramentum" (Tr. in Joan. 8o, 3) no se trata de lo que se llama en escolástica la forma del sacramento, sino de la bendición de Cristo sobre el agua, deviniendo ésta el lugar de una regeneración espiritual. Hay también los textos repetidos donde se dice: Sacramentum nihil est... no hay más que el Espíritu: sola virtus assistens que, con ocasión del sacramento, concurre a producir la gracia. Revelan la manera en que san Agustín comprende la instrumentalidad del signo. Es difícil encontrar las categorías aristotélicas, pero una cierta productividad es admisible. Una tendencia espiritualizante ha impedido a san Agustín admitir pura y simplemente lo que los griegos llamaban causalidad que pasa por la materia" ${ }^{90}$. El teólogo lovaniense se proyectaba hacia una comprensión ocasionalista de esa cierta productividad del sacramento.

Por su parte, Villette ha dedicado unas páginas ${ }^{91}$ al estudio de este texto de san Agustín, que cree sumamente interesante para completar Ja doctrina del sacramento y de la palabra de la fe. Lo examina en su doble aspecto, de constitución del sacramento y de eficacia del mismo. A lo primero se referiría el accedit verbum... y lo demás diría relación con lo segundo. He aquí sus palabras para no desvirtuarlas: "A la segunda cuestión que es saber cómo el alma es purificada en el bautismo, Agustín aporta una respuesta bastante matizada. Menciona sin duda el papel eficaz en sí mismo de la palabra sacramental pero añade que este

90 G. PhILIPS, "Le mystlère du Christ": Augustinus Magister III, Paris 1955, 225, en la disicusión sobre el tema.

9: L. VILLDTTE, F o i et Sacrement. I. Du Nouveau Testament à saint Augustin, Paris 1959, 233-239. 
papel no puede normalmente ejercerse sin la fe de aquellos que reciben el sacramento. No basta que la palabra sea 'dicha' para que el agua purifique, es preciso además que sea 'creída'. El bautismo, consagrado por la palabra, recibe el 'poder de purificar' ( $u t_{1}$ mundare possit), pero no ejerce este poder más que cuando es recibido en la fe" ${ }^{92}$. Todo se comisiona a la fe y a la palabra de la fe, sea en la consagración del agua, sea en la eficacia del sacramento. Y resume así el pensamiento: "En resumen, el efecto del bautismo está explicado aquí por la intervención concomitante de dos factores: de una parte el contenido objetivo de la palabra sacramental (verbum fidei quod praedicamus), y de otra, la recepción subjetiva de este mensaje: la fe del creyente (quia creditur )" ${ }^{93}$. Y concluye con estas palabras: "Es, pues, cierto, en virtud de estos precedentes dogmáticos que en el Tractatus 80 la 'palabra de fe' por la que es consagrado el bautismo representa una realidad objetiva y permanente, es decir la 'doctrina cristiana' en general, y más precisamente sin duda la fe en la Trinidad y en Cristo salvador. No se trata en manera alguna de la fe interior de los ministros o de los catecúmenos. Este acercamiento entre la palabra y la fe no introduce parte alguna de subjetivismo en la constitución válida del sacramento. La palabra no consagra el bautismo porque sea dicha o recibida por tal o cual, sino en razón de su virtud interna, de su contenido objetivo. El sacramento está constituído en sí mismo por el misterio de la fe que expresa; está consagrado por el objeto mismo que significa. Agustín no corrige, pues, en nada las conclusiones formales que ha sembrado todo a lo largo de los tratados antidonatistas; permanece en una concepción estrictamente realista del sacramento. El inmenso interés del Tract. 80 y de los textos que lo preparan en las obras anteriores, radica en mostrar cómo esta concepción estrictamente realista se funda en definitiva sobre la afirmación de un lazo metafísico entre la realidad sacramental y la fe" ${ }^{94}$.

UNA visióN DE CONJUNTO.

Analizados los diferentes elementos que se han integrado a la compleja noción de sacramento y el empleo múltiple que se hace del término, nos toca ahora extraer las concliusiones. Estas nos permitirán avistar

92 ID., o. c., 234.

9/3 ID., o. c., 235.

$9 / 4$ ID., o. c., 239. 
Ia idea directiva por la que nos preguntábamos al principio, idea que sin duda ha latido a través de todas las controversias, manifestándose con matices diversos.

Parecería lógico que en el clima platónico en que se ha movido el pensamiento de Agustín nos encontráramos con cuanto hemos apreciado. Y también en este sentido Ambrosio ha ejercido un influjo sobre san Agustín ${ }^{95}$. En el platonismo el problema planteado era la relación entre el mundo de lo inteligible y el mundo de lo sensible, el posible influjo del espíritu sobre la materia y el cómo del mismo. A este propósito pueden recordarse con utilidad los sondeos de Agustín en el lib. VI De musica y un poco en el De quantitate animiate, hablando de la sensación como passio y el cómo de ésta. Al trasladarse los problemas filosóficos a la religión, se trataba del influjo de Cristo o del Espíritu sobre lo material, o cómo puede algo material producir una gracia que es espiritual o invisible. He aquí sin duda el planteamiento del tema, que, en retrospectiva, puede aclararnos cuanto hemos dicho.

Con cuanto hemos estudiado hasta el presente, podríamos plantearnos así una especie de definición de sacramento en Agustín: El sacramento es un signo sagrado, es decir que dice rellación a las cosas divinas, o sela una realidad (res) que, además de la lesplecie que ofrede a los sentidos (de lo visible y sensible), por sí mismo (ex se) hace venir a la consciencia otra realidad, que es la invisible.

Y nos preguntamos nuevamente: ¿Qué relación existe entre lo visible y lo invisible en general? ¿Puede lo visible ser causa de lo invisible? ¿Puede Dios disponer positivamente que así sea? ¿Cómo actúa lo visible en lo invisible? ¿Es producido esto por su medio o no? En otros términos, ¿llega Agustín al concepto de causalidad, tal como se ha comprendido posteriormente en el tratado de sacramentos? Los autores se han dividido. Recogemos algunas opiniones. Kornyljak concluye su tesis de este modo: "Dignoscendum est Episcopum Hipponensem non sufficienter inter efficacitatem ritus et actionem Ecclesiae in dispensatione gratiae distinguisse. Non est ritus qui gratiam producit, sed est Deus qui subjecto eam communicat. Conceptus sacramenti tanquam causae verae et propriae in considerationem S. Doctoris non cadit. S. Augustinus opus ministri et subjecti in productione gratize clare exposuit, tamen eadem cum claritate de efficacitate ritus non loquitur, nam ad abstrac-

95 Vid. nota 10. El tema lo tenemos en estudio, pero de las investigaciones realizadas puede probarse la afirmación. 
tam notionem causalitatis non pervenit" ${ }^{96}$. En contraposición había dicho antes Portalié: "Conclusión: Agustín ha verdaderamente enseñado la eficacia de los sacramentos, tal como la escolástica y más tarde la Iglesia han querido expresarla por la fórmula ex opere oplerato. Cf. Cont. Cresc. I. IV, c. XVI, n. 19, PL., t. XLIII, col. 559: Non corum meritis a quibus ministratur, nea eorum quibus ministratur, constat baptismus, sed propria sanctitate atque veritate propter eum a quo institutus est, bene utentibus ad salutem" 97. En torno a la eficacia del sacramento, Tixeront escribe también lo siguiente: "En estas concepciones, el papel del rito es simbolizar, significar exterionmente el efecto de la gracia directamente producida por el Espíritu Santo o por Jesucristo más bien que ser propiamente la causa" ${ }^{98}$.

En el Congreso agustiniano de 1954 hubo una sostenida discusión sobre el tema y alguien con valentía y maestría, insistiendo en el espiritualismo agustiniano, llegaba a conclusiones con las que no todos estaban conformes. Su tema era "el Cristo-Jefe y su cuerpo místico" y por tanto tenía que hablar de su influjo en los miembros. Y con este tema venía en relación forzada el sacramento. Decía así: "La causalidad de los sacramentos, en san Agustín, está muy cerca del ocasionalismo, aun si los escolásticos han invocado su autoridad para hacer reconocer en los signos rituales verdaderas "causas" de la gracia. La misma mentalidad general ha impedido a este gran genio valorizar plenamente la presencia sustancial del cuerpo de Jesús bajo las especies consagrables. Su pensamiento camina de conjunto sobre el efecto ulterior: la unidad de todos los miembros en la comunión eclesial.

"Por todas partes constatamos la misma tendencia a espiritualizar y la misma preocupación pastoral por evitar el ritualismo y las deformaciones materializantes. El Espíritu que comienza su obra en la encarnación, se consagra luego a la divinización de los miembros, pero más bien que obrar por la carne de Cristo, por la Iglesia y por los sacramentos, opera nuestra salud directamente, en nazón de los méritos de Cristo, en la Iglesia y con ocasión de los ritos. El bautismo, la Eucaristía, la pertenencia a la Iglesia son de necesidad de medio, pero únicamente a causa de la presencia del Espíritu del que sólo, la Católica,

\footnotetext{
96 P. V. KoRNYLJAK, Saneti Augustini de efficacitate sacramentorum doctrina contra Donatistas, Romae-Philadel phiae 1953, 133.

97 . E. PORTALIE, "Augustin (saint)": Dictionnaire de Théologie catholique I/2, col. 2417.

98 J. TIXERONT, o. $0 ., 406$.
} 
puede gloriarse. Lo importante, entonces, no es encontrarse corporalmente en el seno de la sociedad de los elegidos, es preciso pertenecer a ella por sus disposiciones de espíritu" "9. Lo que impediría a Agustín atribuir la virtud instrumental a la carne de Cristo, a los misterios y sacramentos del Señor, sería por una parte su deficiente información sobre los Padres orientales, pero sobre todo su formación platónica en la que la materia no es receptiva y es pantalla del espíritu. Su cristianismo había comenzado bajo ese signo. Philips proponía, en el resumen para la discusión, así sus conclusiones: "El Espíritu Santo santifica a los hombres a causa de los méritos de Cristo, en el seno de la Iglesia católica, bajo reserva de la recepción de los ritos sagrados, pero no por la humanidad de Jesús, ni por la Iglesia, ni en rigor de términos, por los sacramentos... Habría querido mostrar que el sacramento, en puro agustinismo, no es la "causa" sino la condición, o, si se prefiere, el principio en sentido amplio de la gracia significada: toda su eficacia depende de la "virtus assistens" del Espíritu Santo" ${ }^{100}$. La discusión se entabló en torno a la causalidad y Philips continuó defendiendo su posición. Por una parte, Smulders habla de textos "minoritarios", escalonados entre su comentario In Romanos y el Enchiridion y Opus imp. contra Julianum, que expresan que el bautismo realiza en el bautizado la muerte y la resurrección de Cristo, fórmula seguramente realista de la acción del sacramento. "Por referencia - termina - a la humanidad de Cristo que es hic et nunc agente de santificación, todo ocasionalismo desaparece". Philips contestaba en estos términos: "Es innegable que algunos textos de Agustín ponen sobne la vía de una causalidad 'productiva', para evitar la palabra latina 'eficiente'. Yo he creído por mucho tiempo que Agustín admitía una cierta producción por el signo sacramental., Lo dice al menos una vez en una frase célebre de la que han usado los escolásticos para atribuirle una causalidad de los sacramentos. Bien, es una hapax y además una expresión figurada, locutio per brevins. La articulación misma del pensamiento conduce a la categoría de signo. ¿La categoría de principio? Sería preciso considerarlo más de cerca. Es manifiesto que Aquel que se ha encarnado es principio por influencia moral en razón de sus méritos, de su muerte, de su resurrección. Pero yo no conozco un texto que exprese el tema alejandrino de una suerte de ema-

99 G. PHILIPs, "Le Christ-Chef et son Corps Mystique": Augustinus Magister II, Paris 1954, 813-814.

100 ID., "Le mystère du Christ": Augustinus Magister III, Paris 1955, 217. 
nación formulable en imágenes biológicas. Yo diría pues que Cristo no es principio más que en sentido de una causalidad moral : mérito, imagen, ejemplo, aliento, evocación, apelo a la fe" ${ }^{101}$. Las objeciones se continúan, insistiendo en la humanidad de Cristo como fuente de gracia y Philips responde con su tesis, que haría del Cristo agustiniano casi un Cristo pelagiano: Por último, ante unas anotaciones de Dalmau, el autor llega a ad'mitir "una cierta productividad, aunque sea difícil hallar las categorías aristotélicas". Dalmau hacía reparar en lo siguiente: "La causalidad es un patrimonio de origen lejano; se verifica en toda acción. Para san Agustín, el sacramentum no es solamente el elemento material, sino todo el compuesto, sobre todo, pues, el elemento divino, el Verbo. En este compuesto, me parece claro que san Agustín admite una verdadera causalidad santificadora, porque todas las condiciones de la causalidad están presentes. Quiere hacernos entender que haya una doble causalidad. Sin duda sería preciso saber cómo san Agustín ha elaborado su teoría" ${ }^{102}$. Al fin de la discusión habría concesiones, pero sin convencimiento. Quizá la respuesta a esas últimas palabras de Dalmau podría hallarse en las páginas presentes.

En un recuento de opiniones como siempre, Moriones en torno a la causalidad y eficacia de los sacramentos se hace estas reflexiones: "Ex his variis interpretationibus jam colligitur, S. Doctorem non satis definite locutum. Hoc unum in mente habet, scilicet, unionem inter signum sacramentalem et rem sacram. Cum minister ritum perficit, Christus aut Spiritus Sanctus gratiam in anima producunt (cf. n. 1918-1919). Hinc saltem theoretice quaestioni de efficacitate sacramentorum solutionem non dedit. Concrete et practice, juxta Kornyljak (c. 128), Augustinus asseruit efficacitatem sacramentorum ut v. g. in effato "Unde ista tanta virtus aquae, ut corpus tangat et cor abluat"? (In Jo. Ev. tr. 8o, 3 ML 35, 1840)" ${ }^{103}$. Dalmau nos hablaba de que Agustín "quiere hacernos entender una doble causalidad" y Moriones expresa que el Santo tiene en la mente "la unión entre el signo sacramental y la realidad sagrada". Todo nuestro empeño ha sido poner de relieve el doble que se patentiza también en sacramentaria.

La pregunta que nos habíamos hecho y que venimos repitiendo continúa en pie y sin respuesta: ¿Qué relación existe entre lo invisible y

\footnotetext{
101 ID., art. cit., 224-225.

102 ID., art. cit., 225, en la discusión en que intervenía Dalmau.

103 F. MORIONES, o. o., 553, nota 7.
} 
lo visible? ¿Es relación de causalidiad, de ocasión, de doncomidantia, o de significación sólo? Vistas las propuestas a este interrogante, pienso que la solución habría que buscarla en la concepción de la gracia, a la que podría reducirse lo invisible de que hemos hablado. $\mathrm{Y}$ ¿qué es la gracia para Agustín? No podemos entrar ahora ampliamente en el tema ${ }^{104}$, pero en síntesis podemos decir que Agustín expresa la gracia como una iluminación, como una inteligiencia, un intellectus fidei, que se demuestra existente a través de unas dielectaclones de fondo, de un amor, de una caridad. La mostración de la existencia de esa gracia en el fondo del alma es la delectación de Cristo en el alma, que es delectación de la verdad, que es amor a los valores superiores, y manifiesta que existe un conocimiento previo o una inteligencia precedente. $\mathrm{Y}$ cuando el amor es consciente, existe una consciencia de esa verdad que se amzba y que era Cristo iluminador y objeto de la iluminación. Agustín está convencido de que la fe puede verse, aunque no su objeto: "Mens quippe humana cum fidlem sudam vided, qua credit quod non videt, non aliquid sempiternum vidlet" ${ }^{105}$. El initium fidei y el pius credulidatis affectus es también una gracia y por tanto gratuito, don, regalo de Dios en el fondo del alma, por donde va a comenzar la justificación. Y esto procede a todo sacramento.

Entonces notamos dos niveles también en la gracia: uno de fondo, de inconsciencia, precedente a toda realización externa y visible, debido a Dios por el Espíritu Santo, o por Cristo y que se opera como santificación invisible del alma, deificándola; y otro, de iluminación, de toma de consciencia, de realización, diríamos de secuencia exterior y visible, debida a los sacramentos por los ministros. El planteamiento cambia así de perspectiva y amplía grandemente la visión. Agustín ha estado empeñado toda su vida en el papel esencial de la fe que se presentará como principio y fundamento de la justificación. Y Agustín la exige también para los sacramentos en su contenido pleno, no como acto explícito sino como contenido que se admite y en el que entran también los sacramentos.

104 Se ha gasitado mucha tinta en el tema y no en vano se ha llamado a Agustín el Doctor de la gracia. Sin embargo pensamos que hay muchos aspectos interesantes sin estudiar, ya que en la intempretación y estudio se han volcado los autores en general a la controversia pelagiana sin tratar de buscar un fundamento más radical a la doctrina.

${ }_{105}$ De Trin. XIV, 2, 4, PL. 42, 1038. El lector avisado advertirá que buscamos la esencia de la gracia actual, mientras que en el bautismo, por ejemplo, se trata de la justificación, gratia gratum faciens. 
El signo sacramental, signo sagrado, no sólo manifiesta, muestra o es la ocasión de que el Espíritu produzca en el alma la gracia, sino que él mismo por sí mismo hace venir a la consciencia otra realidad, distinta de la especie que impresiona en los sentidos. Se trata de una significación factiva que tiene siempre efecto, si no se opone un pensamiento contrario. Y se comprende fácilmente: el signum est res, praxter speciam quam ingerit sensibus, aliquid aliud ex se faciens in cogitationem venire. He aquí la iluminación, la toma de consciencia a que llama y la realización que exige. La santificación invisible precedía como obra del Espíritu y el sacramento da la santificación visible, iluminación en quien es capaz de reflexión y llamada a la misma en el infante. El óbice a que aludía la Epist. 98, ro era precisamente una cogitatio contraria, la existencia de otra fe que impedía la iluminación de ésta. El sacramento como signo haría la gracia en este segundo nivel, es decir la visibilizaría, la humanizaría, haciéndola refleja.

Si quisiéramos responder a la pregunta propuesta, diríamos que entre lo visible y. lo invisible en principio hay marcha paralela y que si preguntamos por la relación entre ambos, respondemos que se trata de una relación de significación factiva, es decir que el signo sagrado no solamente impresiona una especie en los sentidos, sino que hace la iluminación, la inteligencia del misterio en quien es capaz de ello, y en quien no lo es, llama a la misma, y por eso non repetet, sed intelliget sacramentum. Hay una causalidad verdadera pero en distintos planos, y para que la causalidad del sacramento aproveche es preciso que exista la obra del Espíritu que es santificación invisible. Y ésta se visibiliza en el sacramento. Por eso se comprende aquello del Santo: No porque exista ya la santificación invisible por el Espíritu debe despreciarse el sacramento visible, ya que el mero hecho de despreciarlo significaría que la santificación invisible no existe, pues ésta se explicita en y por los sacramentos. A través de los sacramentos se pone de manifiesto que Dios ha obrado ya en las intimidades.

Dejamos para ocasión más propicia hacer las aplicaciones a la vida pastoral y moral de esta concepción sacramentaria del Santo, en la que Cristo ocupa el primer puesto y en la que el hombre divinizado por Cristo y santificado por el Espíritu, tiene que iluminarse, tomar consciencia de cuanto el Espíritu obra enı su interior, sirviéndose de los sacramentos para ello, no sólo por una santificación exterior, sino que por medio de la santificación visible le hace tomar consciencia (in cogi- 
tationem facit venire) de lo interior para que lo realice en la vida. El signo no es ya cósico, sino personal y es una llamada continua a la consciencia, a la iluminación y en ese sentido es también aumento de gracia ${ }^{106}$.

106 Quedan todavía otros puntos sin analizar en la doctrina sacramentaria agustiniana, sobre todo el aspecto del sacramento como lazo de unión entre los miombros de una misma religión. $Y$ es lazo de unión también por lo visible, contando con la cohesión interior por la caridad y la gracia. También en este sentido el sacramento conserva el aspecto que hemos tratado de evidenciar a lo lango de estas páginas. Este panorama unitivo nos lo abren textos como éste. "In nullum autem nomen religionis seu verum, seu falsum, coagulari homines possunt, nisi aliquo signaculorum vel sacramentorum visibilium consortio colligentur: quorum sacramentorum vis inenarrabiliter valet plurimum, et ideo contempta sacrilegos facit. Impie quippe contemnitur, sine qua non potest perfici pietas" (C. Faustum manich. XIX, 11, PL. 42, 355). Y el desprecio de esos sacramentos ya sabemos lo que significa para Agustín en su doctrina sacramentaria. Nos hubiera gustado poner de relieve la fecha de los textos, ya que Agustín fue evolucionando desde sus posturas filosóficas iniciales hacia una concepción "bíblica" del Universo. También nos hubiera gustado poner de relieve esa "ontología teológica" que Agustín fue elaborando para explicar un "pecado original" y una "liberación de ese pecadio". Pero son temas que, por sí solos, requieren estudios especiales.

JOSÉ MORÁN 